\title{
RIGOROUS KINETIC MODELLING WITH EXPLICIT RADIATION ABSORPTION EFFECTS OF THE PHOTOCATALYTIC INACTIVATION OF BACTERIA IN WATER USING SUSPENDED TITANIUM DIOXIDE
}

\author{
Javier Marugán ${ }^{\mathrm{a}}$, Rafael van Grieken ${ }^{\mathrm{a}}$, Cristina Pablos ${ }^{\mathrm{a}}$, \\ M. Lucila Satuf ${ }^{\mathrm{b}}$, Alberto E. Cassano ${ }^{\mathrm{b}}$, Orlando M. Alfano ${ }^{\mathrm{b}}$ \\ ${ }^{a}$ Department of Chemical and Environmental Technology, ESCET, Universidad Rey Juan \\ Carlos, C/ Tulipán s/n, 28933 Móstoles (Madrid), Spain, \\ Tel: +34 91664 7007, Fax +3491488 7068, E-mail: javier.marugan@urjc.es \\ ${ }^{\mathrm{b}}$ Instituto de Desarrollo Tecnológico para la Industria Química (INTEC), (Universidad \\ Nacional del Litoral-CONICET), CCT Santa Fe. Paraje El Pozo. \\ Colectora de la Ruta Nacional N 168, 3000 Santa Fe, Argentina \\ Tel: +54 342 4511546/7, Fax +54 342451 1087, E-mail: alfano@intec.unl.edu.ar
}

Published on

Applied Catalysis B: Environmental, 102: 404-416 (2011).

doi:10.1016/j.apcatb.2010.12.012 


\begin{abstract}
This study is focused on the kinetic modelling of the photocatalytic inactivation of bacteria with suspended $\mathrm{TiO}_{2}$. A rigorous model based on a proposed reaction mechanism and accounting explicitly for the rate of photon absorption has been developed. The application of the general kinetic expression to limiting cases suggests that the interaction bacteria-catalyst can be considered to be weak. In contrast, a complex dependence on the radiation absorption rate must be taken into account, as very different radiation conditions may coexist inside the photoreactor, with high absorption rates in the region near to the radiation entrance window and much lower values on the opposite side of the photoreactor. The model has been successfully validated by experimental data, being able to reproduce the evolution of the concentration of viable bacteria in a wide range of values of $\mathrm{TiO}_{2}$ concentration, irradiation power and initial concentration of bacteria with a normalized root mean square logarithmic error of $5.3 \%$. The values of the kinetic parameters are independent of the specific reactor setup or the operating conditions and therefore, the model can be used in a predictive way for photoreactor design and scaling-up, as well as for the optimization of other reactor configurations.
\end{abstract}

KEYWORDS: photocatalysis, kinetics, disinfection, titanium dioxide, E. coli. 


\section{Introduction}

Water disinfection using $\mathrm{TiO}_{2}$ photocatalysis has attracted increasing scientific interest during the last two decades, as shown by the reviews published in this field [1-3]. This technology avoids the formation of carcinogenic disinfection by-products (DBPs) such as chloro-organic compounds in chlorination processes (generated by the reaction of chlorine-based reactants with naturally occurring organic matter) [4] or bromates in ozonation processes (by reaction of ozone with dissolved bromides) [5]. Moreover, photocatalytic technologies have important advantages over other advanced oxidation processes (AOPs) from the energy consumption and environmental impact viewpoints, such as using air as the oxidant reactant, working under ambient temperature and pressure, and including the possibility of using solar light to drive the process [6].

Although Escherichia coli is, by far, the most studied organism [1-2], literature reports on photocatalytic disinfection demonstrate the feasibility of inactivation of different kinds of microorganisms apart from bacteria, such as viruses [7,8], algae [9], fungi [10], yeasts [11] or protozoa [12,13]. Operational parameters of the process have been also deeply investigated, including light intensity and titanium dioxide concentration $[11,14,15]$, solar irradiation [16,17] and the use of immobilized [18,19] or silver-modified $\mathrm{TiO}_{2}$ with biocidal power enhancement $[20,21]$. The influence of the chemical composition of water has been also studied [22,23], being this a critical factor in real applications of this technology for drinking water [24] and disinfection of effluents from wastewater treatment plants $[18,25]$. Less efforts, however, have been devoted to the rigorous kinetic description of the process. In most cases, the disinfection profiles are described by very simple empirical models with parameters lacking physical or chemical meaning, whereas the results reported in the literature usually show complex inactivation profiles which cannot be successfully described, for example, by the simple log-linear Chick's Law. A recent review [26] summarizes the main empiric and mechanistic models reported for photocatalytic disinfection, being the distribution of the radiation absorption inside the photoreactor not considered in any of them. In a previous work [23] we developed a kinetic model based on a simplified inactivation mechanism that was able to fit the disinfection results data over a wide range of experimental conditions using 3 kinetic parameters with well-defined physical meaning: kinetic constant, interaction constant and inhibition coefficient. This model is very useful to compare the effect of several operational variables and catalysts modifications on the reaction kinetics [15], but 
does not explicitly consider the radiation profiles inside the photoreactor, leading to equations that are only valid for the experimental setup in which the parameters have been estimated. Consequently, the mechanistic models reported in the literature for photocatalytic disinfection are not valid for photoreactor design and scaling-up purposes.

The dependence of the photocatalytic reaction rates on the irradiation power is usually considered to be linear under low irradiation conditions, but the exponent decreases to 0.5 under moderate to high irradiation power, due to the increase of the relative importance of the second-order electron-hole recombination processes [27-29]. Considering that the existence of radiation profiles inside photocatalytic reactors cannot be avoided due to the intrinsic nature of the process, it should be expected a progressive change in the dependence of the reaction rate on the radiation intensity from values close to 0.5 near the photoreactor irradiated surface to 1.0 in the darker regions. Consequently, equations that correlate macroscopic reaction rate values with the incident irradiation power are only valid for the experimental setup in which they have been developed. An intrinsic kinetic model suitable for further applications in photoreactors design and scaling-up must be based on the evaluation of the local values of the reaction rates and, therefore, on the volumetric rate of photon absorption calculated through the evaluation of the radiation field inside the reactor. This important topic is the subject of investigation by several research groups [30-40].

This work is focused on the development of a rigorous intrinsic kinetic model with explicit radiation absorption effects for microorganism's inactivation photocatalytic processes. The latter approach has been successfully validated for the photocatalytic oxidation of different chemical pollutants such as 4-chlorophenol [39] and cyanide [40] but, to the best of our knowledge, there are no references in the literature to the application of these kinds of models to the inactivation of microorganisms. Despite the significant differences existing between photocatalytic inactivation of microorganisms and photocatalytic oxidation of pollutants due to the microbiological aspects of disinfection processes, in both cases the activation steps are obviously related to the radiation absorption by the semiconductor particles and the subsequent hydroxyl radicals (or other highly reactive oxygen species) generation $[15,41,42]$. A previous attempt with preliminary successful simulation results for experiments with different catalyst concentrations has been reported [43], but this model required a modification with an empirical exponent and, what is more important, was unable to reproduce the results of experiments carried out under increasing 
irradiation power and/or with different initial concentrations of bacteria. For that reason, new efforts were devoted to the development of a kinetic model based on an intrinsic reaction mechanism without any empirical modification, with the conviction that this approach is a more rational way to get kinetic parameters that are independent of the reactor size and geometry and, consequently valid for the design of large scale photocatalytic disinfection reactors.

\section{Experimental}

\subsection{Photoreactor}

The experimental setup for the photocatalytic reactions is schematized in Figure 1. The annular photoreactor $(15 \mathrm{~cm}$ long, $3 \mathrm{~cm}$ inner diameter and $5 \mathrm{~cm}$ outer diameter) made of borosilicate glass operates in a closed recirculating circuit driven by a centrifugal pump; the system is completed with a well-stirred reservoir tank having a device for withdrawal of samples. The total working volume is equal to $1 \mathrm{~L}$. The suspension flow rate was set at $2.5 \mathrm{~L}$ $\min ^{-1}$, being the estimated Reynolds dimensionless number of 663 . That means that the system is theoretically operating under laminar flow regime. However, good mixing conditions are assured by the short length of the reactor and the turbulence generated at the reactor entrance (the inlet suspension impact directly against the reactor wall). The small reactor volume and the relatively slow kinetics of the process allow the assumption of differential conversion per pass. Under these special conditions and in the absence of mass transfer limitations, the flow regime has almost no effect on the kinetics and, consequently, in the interpretation of the experimental data. Good aeration conditions were maintained in the reservoir tank to provide the dissolved oxygen required for the reaction.

\section{FIGURE 1}

A Philips TL 6W/08 black light blue lamp with a maximum emission at 370-375 nm was placed in the axis of the annulus. The length of the lamp is $21 \mathrm{~cm}$, being both extremes outside the reactor to avoid end-effects and allow the assumption of uniform superficial emission. Radiation enters the photoreactor through the inner wall after crossing a neutral filter that controls the irradiation power (Figure 1). Neutral filters consist of a polymeric 
substrate in which a controlled black coverage level is achieved by high-quality laser printing using CorelDraw ${ }^{\circledR}$ software. The reproducibility and stability of the filters after several hours of irradiation have been positively verified by checking the intensity and spectrum of the filtered UV radiation with a Gigahertz-Optik X97 irradiance meter and a Varian Cary 500 Scan UV-Vis-NIR spectrophotometer, respectively. In all experiments, the lamp was switched on $15 \mathrm{~min}$ before the reaction starts to stabilize its emission power and spectrum. Figure 2 shows the spectral distribution of the entering radiation and the neutral filters transmittance. The total irradiation power was calculated from potassium ferrioxalate actinometry experiments.

\section{FIGURE 2}

All the components of the system are covered with black clothes to avoid uncontrolled irradiation. A wet, dense black fabric is used to maintain the temperature of the reservoir tank below $30^{\circ} \mathrm{C}$, a requirement to obtain a good reproducibility in microbiological experiments.

\subsection{Photocatalytic experiments}

Disinfection experiments have been carried out using suspensions of Degussa P25 $\mathrm{TiO}_{2}$. This photocatalyst has been widely studied in the literature and its physicochemical and optical properties have been previously reported [44, 45]. Figure 2 shows the spectral distribution of the specific volumetric absorption coefficient of Degussa $\mathrm{P} 25 \mathrm{TiO}_{2}$ suspensions at natural $\mathrm{pH}$. To show photocatalytic activity, this absorption spectrum must obviously have a reasonable degree of overlapping with the spectrum of the radiation entering the reactor (also shown in Figure 2).

Escherichia coli K-12 strains were provided lyophilized by the Spanish Type Culture Collection (CECT 4624, corresponding to ATCC 23631). This bacterium was selected as indicator microorganism for disinfection experiments due to its wide use for detection of faecal contamination of water. Fresh bacterial cultures of around $10^{9} \mathrm{CFU} \mathrm{mL} \mathrm{m}^{-1}$ of stationary concentration were prepared by inoculation of $20 \mathrm{~mL}$ of Luria-Bertani nutrient medium (Miller's LB Broth, Scharlab) and aerobic incubation at $37^{\circ} \mathrm{C}$ under rotary shaking for $24 \mathrm{~h}$. Reacting suspensions were prepared by centrifuging $5 \mathrm{~mL}$ of the liquid culture at $3000 \mathrm{rpm}$ 
for 15 minutes, rinsing twice the bacteria with $5 \mathrm{~mL}$ of sterile ultra-pure water (Milli-Q ${ }^{\circledR}$, $18.2 \mathrm{M} \Omega \mathrm{cm}$ ) and finally diluting $1 \mathrm{~mL}$ of the aqueous $E$. coli suspension to 1 L to get an initial concentration of viable bacteria around $10^{6} \mathrm{CFU} \mathrm{mL}^{-1}$. Experiments with lower initial concentration of bacteria were prepared taking the corresponding volume of the E. coli suspension.

The bacterial suspension and the catalyst were charged in the reservoir tank and the recirculation pump was switched on 15 minutes for the equilibration of the system. In the meantime, the lamp was switched on outside the reactor to stabilize its emission power and spectrum before the reaction starts. The evolution of the reaction was followed quantifying the concentration of viable bacteria by a standard serial dilution method using LB nutrient agar plates (Miller's LB Agar, Scharlab). Eight replicates of each decimal dilution were incubated at $37^{\circ} \mathrm{C}$ for $24 \mathrm{~h}$ before counting the number of bacterial colony forming units (CFU). Larger volumes $(100 \mu \mathrm{L}$ and $1 \mathrm{~mL})$ of the undiluted suspension were also plated for samples taken at longer irradiation times, in which a very low bacterial concentration is expected, to reduce the limit of detection below $1 \mathrm{CFU} \mathrm{mL} \mathrm{m}^{-1}$. Key experiments were repeated to test the reproducibility of the disinfection results.

\section{Kinetic modelling}

\subsection{Derivation of the kinetic model}

The photocatalytic inactivation of bacteria can be modelled in a simple way by a series events reaction mechanism in which bacteria require a number of incremental damages until become inactivated and finally lysed [23]. The kinetic model proposed for the photocatalytic disinfection of Escherichia coli suspensions is based on a different concept as shown in the reaction scheme summarized in Table 1.

Figure 3 shows the main reaction pathway proposed for the undamaged $\left(B_{u}\right)$, damaged $\left(\mathrm{B}_{\mathrm{d}}\right)$ and inactivated $\left(\mathrm{B}_{\mathrm{i}}\right)$ population of bacteria, and for the biological structures and compounds released after the bacterial lysis $\left(\mathrm{B}_{\mathrm{pi}}\right.$, with $i=1$ to $\left.n\right)$.

\section{FIGURE 3}


Appendix A shows the details of the derivation of the kinetic model and the assumptions considered to obtain the following kinetic expressions:

$$
\begin{aligned}
& R_{u}\left(\frac{\mathrm{CFU}}{\mathrm{s} \mathrm{cm}^{3}}\right)=-\alpha_{1}\left(\frac{K_{a d s} C_{c a t}}{1+K_{a d s} C_{c a t}}\right) \frac{\left[\mathrm{B}_{\mathrm{u}}\right]^{2}}{\left[\mathrm{~B}_{\mathrm{u}}\right]+\alpha_{4}\left[\mathrm{~B}_{\mathrm{d}}\right]+\alpha_{3}[\mathrm{~B}]_{0}-\left[\mathrm{B}_{\mathrm{u}}\right]-\left[\mathrm{B}_{\mathrm{d}}\right]}\left[-1+\sqrt{1+\frac{\alpha_{2} e^{a}}{S_{g} C_{c a t}}}\right] \\
& R_{d}\left(\frac{\mathrm{CFU}}{\mathrm{s} \mathrm{cm}^{3}}\right)=\alpha_{1}\left(\frac{K_{a d s} C_{c a t}}{1+K_{a d s} C_{c a t}}\right) \frac{\left[\mathrm{B}_{\mathrm{u}}\right]^{2}-\alpha_{4}\left[\mathrm{~B}_{\mathrm{d}}\right]^{2}}{\left[\mathrm{~B}_{\mathrm{u}}\right]+\alpha_{4}\left[\mathrm{~B}_{\mathrm{d}}\right]+\alpha_{3}[\mathrm{~B}]_{0}-\left[\mathrm{B}_{\mathrm{u}}\right]-\left[\mathrm{B}_{\mathrm{d}}\right]}\left[-1+\sqrt{1+\frac{\alpha_{2} e^{a}}{S_{g} C_{c a t}}}\right]
\end{aligned}
$$

where $R_{u}$ and $R_{d}$ are the reaction rate for undamaged and damaged bacteria, respectively, [ $\mathrm{B}_{\mathrm{u}}$ ] and $\left[B_{d}\right]$ are the concentration of undamaged and damaged bacteria, $[B]_{0}$ is the initial concentration of bacteria, $e^{a}$ the local volumetric rate of photon absorption (LVRPA), $S_{g}$ the catalyst specific surface area, $C_{c a t}$ the catalyst mass concentration, $K_{a d s}$ the equilibrium adsorption constant, and $\alpha_{1}, \alpha_{2}, \alpha_{3}, \alpha_{4}$ are kinetic parameters. It has to be highlighted that the proposed kinetic model provides a general rate expression with an explicit dependence of the photon absorption effects on the bacterial inactivation rate.

\subsection{Estimation of the kinetic parameters}

Figure 4 schematizes the procedure for the estimation of the intrinsic kinetic parameters. The calculation of the reaction rate is carried out in every position of the reactor, which requires the preliminary evaluation of the local volumetric rate of photon absorption (LVRPA, $e^{a}$ ) in every position of the annular photoreactor as a function of the incident irradiation power and the catalyst concentration. Assuming that the optical properties of the suspension do not vary during the reaction (there is no formation or disappearance of absorbing species or significant changes in the $\mathrm{pH}$ value that could modify the aggregation of the catalyst particles), the LVRPA distribution evaluated inside the photoreactor can be considered to be constant with time. The values of $e^{a}$ can be calculated by integration over the wavelength range in which there is overlapping between the photocatalyst absorption and incident radiation spectra, i.e. $340-400 \mathrm{~nm}$ according to Figure 2 (the absorption of radiation by bacteria in the wavelength range of $340-400 \mathrm{~nm}$ has been experimentally verified to be negligible). The integrand is the product of the monochromatic absorption coefficient and the 
total incident monochromatic radiation, calculated through the integration of the monochromatic intensities over the whole spherical space of directions:

$$
e^{a}=\int_{\lambda_{1}}^{\lambda_{2}} \kappa_{\lambda}(\underline{x}) \cdot \int_{\Omega=4 \pi} I_{\lambda, \underline{\Omega}}(\underline{x}) \mathrm{d} \Omega \mathrm{d} \lambda
$$

\section{FIGURE 4}

The value of the monochromatic radiation intensity for each direction of the spherical space and for each differential elementary volume of the reactor can be calculated by the resolution of the radiative transfer equation (RTE) that describes the transport of photons through an absorbing and scattering medium such as a $\mathrm{TiO}_{2}$ suspension. A detailed description of the numerical procedure for the resolution of the RTE using a 2-dimensional 2directional radiation model can be found elsewhere [40]. The main difference with the procedure reported in the mentioned reference is the determination of the radiation inlet boundary condition, because diffuse inlet irradiation (equal intensities in all the directions) cannot be assumed in the present lamp-reactor arrangement. In this case, the radiation emitted by the lamp is discretized into the different directions using a superficial diffuse emission model to take into account the geometry of the system [46]. This model has been previously validated for a larger scale annular photocatalytic reactor for the oxidation of cyanide [47].

Once the values of the reaction rate in every position of the reactor have been computed, they can be used to solve the mass balance of the system. Assuming that: i) the system is perfectly mixed; ii) there are no mass transport limitations; iii) the conversion per pass in the reactor is differential; and iv) parallel dark reactions can be neglected, the mass balance of undamaged and damaged bacteria in the reservoir tank can be expressed as follows:

$$
\begin{array}{ccc}
\left.\frac{\mathrm{d} \mathrm{B}_{\mathrm{u}} t}{\mathrm{~d} t}\right|_{\text {Tank }}=\frac{V_{\text {Reactor }}}{V_{\text {Total }}}\left\langle R_{u}(\underline{x}, t)\right\rangle_{V_{\text {Reactor }}} & t=0 & {\left[\mathrm{~B}_{\mathrm{u}}\right]=[\mathrm{B}]_{0}} \\
\left.\frac{\mathrm{d} \mathrm{\textrm {B } _ { \mathrm { d } } t}}{\mathrm{d} t}\right|_{\text {Tank }}=\frac{V_{\text {Reactor }}}{V_{\text {Total }}}\left\langle R_{d}(\underline{x}, t)\right\rangle_{V_{\text {Reactor }}} & t=0 & {\left[\mathrm{~B}_{\mathrm{d}}\right]=0}
\end{array}
$$


where $V$ is the volume; Tank, Reactor and Total subscripts refer to the reservoir tank, photoreactor and total recirculation system, respectively; $t$ denotes reaction time; and $\langle R \underline{x}, t\rangle_{V_{\text {Reactor }}}$ is the reactor volume-averaged volumetric rate of undamaged and damaged bacteria disappearance, referred by subscripts $u$ and $d$, respectively. This average reaction rate can be estimated from the values of the local reaction rates calculated from the intrinsic kinetic model (Eqs. 1 and 2).

The resolution of the mass balance equations renders the evolution of both undamaged and damaged bacteria on the reservoir tank. These values can be compared with the experimental results obtained for viable bacteria according to the following definitions:

$$
\begin{aligned}
& C^{\text {Calc }} t=\mathrm{B}_{u} t+\mathrm{B}_{d} t \\
& \left(\frac{C}{C^{0}}\right)^{\text {Calc }} t=\frac{\mathrm{B}_{u} t+\mathrm{B}_{d} t}{\mathrm{~B}_{0}}
\end{aligned}
$$

considering that both undamaged and damaged bacteria remain viable and consequently are computed by the plating technique. Using a nonlinear regression algorithm (Figure 4), the values of the intrinsic kinetic parameters that best fit all the different experiments under varied operating conditions can be estimated.

\section{Results and Discussion}

Experimental data for the verification of the kinetic model have been obtained in a wide range of values of catalyst loading, irradiation power and initial concentration of bacteria. The results show the expected effect of each variable with increasing activity for higher catalyst concentrations and irradiation power as well as the longer irradiation times required for the inactivation of higher initial concentrations of bacteria. Apart from these obvious experimental conclusions, the goal of this work is to obtain the values of the kinetic parameters that best reproduce the activity results according to the model previously described under different experimental conditions. 


\subsection{General kinetic model}

Figure 5 shows the good agreement between the prediction of the model and the experimental data obtained in disinfection reactions carried out under different catalyst concentrations, irradiation power and initial concentration of bacteria. The values of the kinetic parameters and the normalized root mean square logarithmic error (NRMSLE) are:

$$
\begin{aligned}
& \alpha_{1}=(8.87 \pm 5.11) \times 10^{1} \mathrm{~s}^{-1} \\
& \alpha_{2}=(3.59 \pm 1.57) \times 10^{11} \mathrm{~cm}^{2} \mathrm{~s}_{\text {Einstein }}{ }^{-1} \\
& \alpha_{3}=(2.45 \pm 3.02) \times 10^{-6} \\
& \alpha_{4}=(1.27 \pm 1465) \times 10^{-1} \\
& K_{a d s}=(8.92 \pm 1472) \times 10^{-1} \mathrm{~cm}^{3} \mathrm{~g}^{-1} \\
& \text { NRMSLE }=5.3 \%
\end{aligned}
$$

\section{FIGURE 5}

It can be noticed that although the model successfully reproduces the experimental results, the values of the kinetic parameters are affected by unacceptable large confidence intervals (especially $\alpha_{4}$ and $K_{a d s}$ ), thus indicating the statistical interaction between some of them and that at least one parameter could be eliminated from the model, considering the following limiting cases: (i) low or high bacteria-catalyst interaction and/or (ii) low or high irradiation power.

\subsection{Limiting cases for bacteria-catalyst interaction}

The general kinetic model previously analysed (Eqs. 1 and 2) considers that the reaction rate is affected by the bacteria-catalyst interaction through the expression:

$\frac{K_{a d s} C_{c a t}}{1+K_{a d s} C_{c a t}}$, which presents two limiting cases for low and high values of the $K_{a d s}$ bacteriacatalyst interaction constant.

\subsubsection{Low bacteria-catalyst interaction}


For low values of $K_{a d s}$ it can be assumed that the product $K_{a d s} C_{c a t}<<1$, leading to the following simplification of the kinetic model equations:

$$
\begin{aligned}
& R_{u}\left(\frac{\mathrm{CFU}}{\mathrm{s} \mathrm{cm}^{3}}\right)=-\alpha C_{c a t} \frac{\left[\mathrm{B}_{\mathrm{u}}\right]^{2}}{\left[\mathrm{~B}_{\mathrm{u}}\right]+\alpha_{4}\left[\mathrm{~B}_{\mathrm{d}}\right]+\alpha_{3}[\mathrm{~B}]_{0}-\left[\mathrm{B}_{\mathrm{u}}\right]-\left[\mathrm{B}_{\mathrm{d}}\right]}\left[-1+\sqrt{1+\frac{\alpha_{2} e^{a}}{S_{g} C_{c a t}}}\right] \\
& R_{d}\left(\frac{\mathrm{CFU}}{\mathrm{s} \mathrm{cm}^{3}}\right)=\alpha C_{c a t} \frac{\left[\mathrm{B}_{\mathrm{u}}\right]^{2}-\alpha_{4}\left[\mathrm{~B}_{\mathrm{d}}\right]^{2}}{\left[\mathrm{~B}_{\mathrm{u}}\right]+\alpha_{4}\left[\mathrm{~B}_{\mathrm{d}}\right]+\alpha_{3}[\mathrm{~B}]_{0}-\left[\mathrm{B}_{\mathrm{u}}\right]-\left[\mathrm{B}_{\mathrm{d}}\right]}\left[-1+\sqrt{1+\frac{\alpha_{2} e^{a}}{S_{g} C_{c a t}}}\right]
\end{aligned}
$$

where $\alpha=\alpha_{1} K_{a d s}$

The values estimated for the kinetic parameters that best reproduced the experimental data are:

$$
\begin{aligned}
& \alpha=(7.82 \pm 0.35) \times 10^{1} \mathrm{~cm}^{3} \mathrm{~g}^{-1} \mathrm{~s}^{-1} \\
& \alpha_{2}=(3.66 \pm 0.43) \times 10^{11} \mathrm{~cm}^{2} \text { s Einstein }^{-1} \\
& \alpha_{3}=(2.44 \pm 0.51) \times 10^{-6} \\
& \alpha_{4}=(1.28 \pm 0.53) \times 10^{-1} \\
& \text { NRMSLE }=5.3 \%
\end{aligned}
$$

As shown in Figure 6, this four-parameter kinetic model correlates all the experiments with a very good agreement and the same value of error (NRMSLE) that the original fiveparameter kinetic model. Moreover, the confidence intervals for the parameters are substantially narrower, confirming the increased statistical significance of the new kinetic equations. Finally, the residuals calculated as the differences between the values predicted by the model and the experimental data are randomly distributed against the absolute value of the bacterial concentration and the three experimental variables (see Figure B1 in Appendix B), confirming that the error of the model can be assumed to be homogeneously distributed around the studied experimental range.

\section{FIGURE 6}




\subsubsection{High bacteria-catalyst interaction}

On the opposite limiting case, for high values of $K_{a d s}$, it can be assumed that $K_{a d s} C_{c a t}>>1$, leading to the following simplification of the kinetic model equations:

$$
\begin{aligned}
& R_{u}\left(\frac{\mathrm{CFU}}{\mathrm{s} \mathrm{cm}^{3}}\right)=-\alpha_{1} \frac{\left[\mathrm{B}_{\mathrm{u}}\right]^{2}}{\left[\mathrm{~B}_{\mathrm{u}}\right]+\alpha_{4}\left[\mathrm{~B}_{\mathrm{d}}\right]+\alpha_{3}[\mathrm{~B}]_{0}-\left[\mathrm{B}_{\mathrm{u}}\right]-\left[\mathrm{B}_{\mathrm{d}}\right]}\left[-1+\sqrt{1+\frac{\alpha_{2} e^{a}}{S_{g} C_{c a t}}}\right] \\
& R_{d}\left(\frac{\mathrm{CFU}}{\mathrm{s} \mathrm{cm}^{3}}\right)=\alpha_{1} \frac{\left[\mathrm{B}_{\mathrm{u}}\right]^{2}-\alpha_{4}\left[\mathrm{~B}_{\mathrm{d}}\right]^{2}}{\left[\mathrm{~B}_{\mathrm{u}}\right]+\alpha_{4}\left[\mathrm{~B}_{\mathrm{d}}\right]+\alpha_{3}[\mathrm{~B}]_{0}-\left[\mathrm{B}_{\mathrm{u}}\right]-\left[\mathrm{B}_{\mathrm{d}}\right]}\left[-1+\sqrt{1+\frac{\alpha_{2} e^{a}}{S_{g} C_{c a t}}}\right]
\end{aligned}
$$

where $K_{a d s}$ disappears as kinetic parameter. This four-parameter kinetic model is unable to reproduce the experimental data, especially in the case of experiments conducted under different catalyst concentrations. In fact, it predicts that a higher value of $C_{c a t}$ leads to a decrease in the inactivation rate, a behavior opposite to the experimental results. Although this trend could be possibly observed for very high values of the catalyst concentration, it is unacceptable for the moderate values of $\mathrm{TiO}_{2}$ concentrations commonly used in photocatalytic inactivation of bacteria.

\subsection{Limiting cases for irradiation power}

Concerning the influence of the irradiation power, the general kinetic model considers that the reaction rate is explicitly affected by the rate of radiation absorption through the expression: $\left[-1+\sqrt{1+\frac{\alpha_{2} e^{a}}{S_{g} C_{c a t}}}\right]$, which also presents two limiting cases for low and high values of the local volumetric rate of photon absorption $\left(e^{a}\right)$. The application of these limiting cases to the four-parameter kinetic model derived for high bacteria-catalyst interaction also leads to senseless predictions of the effect of the catalyst concentration. Consequently, the limiting cases for irradiation power will be only considered on the four-parameter kinetic model derived for low bacteria-catalyst interaction. 


\subsubsection{Low irradiation power}

For low values of the irradiation power and therefore of the rate of radiation absorption, it can be assumed that $\frac{\alpha_{2} e^{a}}{S_{g} C_{c a t}}<<1$ and consequently the square root can be approximated by the first term of the Taylor series expansion $(\sqrt{1+x} \approx x / 2)$ [30], leading to the following simplification of the kinetic model equations:

$$
\begin{aligned}
& R_{u}\left(\frac{\mathrm{CFU}}{\mathrm{s} \mathrm{cm}^{3}}\right)=-\alpha \frac{1}{S_{g}} \frac{\left[\mathrm{B}_{\mathrm{u}}\right]^{2}}{\left[\mathrm{~B}_{\mathrm{u}}\right]+\alpha_{4}\left[\mathrm{~B}_{\mathrm{d}}\right]+\alpha_{3}[\mathrm{~B}]_{0}-\left[\mathrm{B}_{\mathrm{u}}\right]-\left[\mathrm{B}_{\mathrm{d}}\right]} e^{a} \\
& R_{d}\left(\frac{\mathrm{CFU}}{\mathrm{s} \mathrm{cm}^{3}}\right)=\alpha \frac{1}{S_{g}} \frac{\left[\mathrm{B}_{\mathrm{u}}\right]^{2}-\alpha_{4}\left[\mathrm{~B}_{\mathrm{d}}\right]^{2}}{\left[\mathrm{~B}_{\mathrm{u}}\right]+\alpha_{4}\left[\mathrm{~B}_{\mathrm{d}}\right]+\alpha_{3}[\mathrm{~B}]_{0}-\left[\mathrm{B}_{\mathrm{u}}\right]-\left[\mathrm{B}_{\mathrm{d}}\right]} e^{a}
\end{aligned}
$$

where $\alpha=\frac{\alpha_{1} \alpha_{2} K_{a d s}}{2}$

It can be noticed that this three-parameter kinetic model predicts a linear dependence of the reaction rate on the radiation absorption rate, in agreement with the behavior reported by other research groups for low radiation fluxes [27].

The values of the kinetic parameters that best reproduced the experimental data are:

$$
\begin{aligned}
& \alpha=(4.02 \pm 0.18) \times 10^{12} \mathrm{~cm}^{5} \mathrm{~g}^{-1} \text { Einstein }^{-1} \\
& \alpha_{3}=(9.82 \pm 0.73) \times 10^{-6} \\
& \alpha_{4}=(1.76 \pm 0.77) \times 10^{-1} \\
& \text { NRMSLE }=7.4 \%
\end{aligned}
$$

As it can be noticed, the value of the error is higher than that of the previously analyzed models. Figure 7 shows that the experiments carried out using different catalyst concentrations and initial concentrations of bacteria are reasonably reproduced, especially considering that Eqs. (10) and (11) do not show an explicit effect of $C_{c a t}$ (the effect of the catalyst concentration is implicitly considered in the evaluation of the radiation absorption). 
However, the effect of the irradiation power is clearly overestimated showing a higher influence on the concentration of bacteria than that experimentally observed. This is verified by the distribution of the residuals against the irradiation power shown in Figure B2 (Appendix B), in which a deviation from a random clear trend is observed, from positive errors for low irradiation power to negative errors for higher values of $P^{0}$.

\section{FIGURE 7}

\subsubsection{High irradiation power}

On the opposite limiting case, for high values of the irradiation power and, therefore, of the rate of radiation absorption, it can be assumed that $\frac{\alpha_{2} e^{a}}{S_{g} C_{c a t}}>>1$, what leads to the following simplification of the kinetic model equations:

$$
\begin{aligned}
& R_{u}\left(\frac{\mathrm{CFU}}{\mathrm{s} \mathrm{cm}^{3}}\right)=-\alpha \sqrt{\frac{C_{c a t}}{S_{g}}} \frac{\left[\mathrm{B}_{\mathrm{u}}\right]^{2}}{\left[\mathrm{~B}_{\mathrm{u}}\right]+\alpha_{4}\left[\mathrm{~B}_{\mathrm{d}}\right]+\alpha_{3}[\mathrm{~B}]_{0}-\left[\mathrm{B}_{\mathrm{u}}\right]-\left[\mathrm{B}_{\mathrm{d}}\right]} \sqrt{e^{a}} \\
& R_{d}\left(\frac{\mathrm{CFU}}{\mathrm{s} \mathrm{cm}^{3}}\right)=\alpha \sqrt{\frac{C_{c a t}}{S_{g}}} \frac{\left[\mathrm{B}_{\mathrm{u}}\right]^{2}-\alpha_{4}\left[\mathrm{~B}_{\mathrm{d}}\right]^{2}}{\left[\mathrm{~B}_{\mathrm{u}}\right]+\alpha_{4}\left[\mathrm{~B}_{\mathrm{d}}\right]+\alpha_{3}[\mathrm{~B}]_{0}-\left[\mathrm{B}_{\mathrm{u}}\right]-\left[\mathrm{B}_{\mathrm{d}}\right]} \sqrt{e^{a}}
\end{aligned}
$$

where $\alpha=\alpha_{1} \sqrt{\alpha_{2}} K_{a d s}$

The values of the kinetic parameters that best reproduce the experimental data are:

$$
\begin{aligned}
& \alpha=(3.87 \pm 0.12) \times 10^{7} \mathrm{~cm}^{4} \mathrm{~g}^{-1} \mathrm{~s}^{-0.5} \text { Einstein }^{-0.5} \\
& \alpha_{3}=(2.06 \pm 0.54) \times 10^{-6} \\
& \alpha_{4}=(1.62 \pm 0.55) \times 10^{-1} \\
& \text { NRMSLE }=5.5 \%
\end{aligned}
$$

In this case, despite the elimination of one parameter, the error is only slightly higher than the ones obtained with eqs. [8] and [9]. The simulated results (Figure 8) show that once again the model successfully predicts the effect of the catalyst concentration and the initial 
concentration of bacteria, although underestimates slightly the effect of the irradiation power. This is again verified by the distribution of residuals shown in Figure B3 (Appendix B), in which a non random variation from negative errors at low values of the irradiation power to positive errors for higher irradiation power is observed.

\section{FIGURE 8}

\section{Conclusions}

The kinetic model for the photocatalytic inactivation of bacteria developed in this work has been successfully validated by experimental data, being able to reproduce the evolution of the concentration of viable bacteria in a wide range of values of $\mathrm{TiO}_{2}$ concentration, irradiation power and initial concentration of bacteria with a normalized root mean square logarithmic error of $5.3 \%$.

The application of the general kinetic expression to limiting cases suggests that the interaction bacteria-catalyst can be considered to be weak, which allows the simplification of the model by removing one parameter. This approximation is able to reproduce all the experimental data with only 4 kinetic parameters.

In contrast, limiting cases for the irradiation power and radiation absorption show that the process operates under an intermediate regime between the linear behavior with respect to the LVRPA usually reported for low irradiation fluxes and the square-root dependence typically observed for moderate to high irradiation fluxes. Both approximations present some deviations in order to reproduce the effect of the irradiation power. The reason is that the photon absorption rate is generally a strong function of position inside the photocatalytic reactor due to the high radiation absorption generated by $\mathrm{TiO}_{2}$ suspensions. Accordingly, both kinetic regimes may coexist inside the same photoreactor, with a high LVRPA in the region near to the radiation entrance window and low values of LVRPA on the opposite part of the photoreactor. Consequently, the general expression of the radiation term must be used to successfully describe the global reaction rate.

The developed model, based on a rigorous reaction mechanism and accounting explicitly for the local volumetric rate of photon absorption, constitutes an intrinsic kinetic 
description of the photocatalytic disinfection process. The values obtained for the kinetic parameters can be considered to be independent of the specific reactor setup or the operating conditions. Therefore, the model could be used in a predictive way for photoreactor design and scaling-up, as well as for the optimization of any other reactor configuration. The validation of this kinetic model in a larger photoreactor will be addressed in future studies.

\section{Acknowledgements}

The authors gratefully acknowledge the financial support of the Ministerio de Ciencia e Innovación through the program Consolider-Ingenio 2010 (project CSD2006-00044 TRAGUA) and the international action PCI2006-A7-0526, Comunidad de Madrid through the program REMTAVARES (S2009/AMB-1588) and from the Universidad Nacional del Litoral, Agencia Nacional de Promoción Científica y Tecnológica, and Consejo Nacional de Investigaciones Científicas y Técnicas of Argentina. Cristina Pablos also acknowledges Ministerio de Ciencia e Innovación for its FPU grant. 


\section{Appendix A. Derivation of the kinetic model.}

The kinetic model proposed for the photocatalytic disinfection of Escherichia coli suspensions is based on the reaction scheme summarized in Table 1. By applying the kinetic micro steady state approximation for the concentration of electrons, holes and hydroxyl radicals, we can derive the following expressions:

$$
\begin{aligned}
& {\left[\mathrm{e}^{-}\right]=\frac{r_{g}}{k_{2}\left[\mathrm{~h}^{+}\right]+k_{3}\left[\mathrm{O}_{2}\right]}} \\
& {\left[\mathrm{h}^{+}\right]=\frac{r_{g}}{k_{2}\left[\mathrm{e}^{-}\right]+k_{4}\left[\mathrm{H}_{2} \mathrm{O}\right]}} \\
& {[\bullet \mathrm{OH}]^{\ell}=\frac{k_{4}\left[\mathrm{~h}^{+}\right]\left[\mathrm{H}_{2} \mathrm{O}\right]}{\ell k_{5}\left[\mathrm{~B}_{\mathrm{u}}\right]+\ell k_{6}\left[\mathrm{~B}_{\mathrm{d}}\right]+\ell k_{7}\left[\mathrm{~B}_{\mathrm{i}}\right]+\ell \sum_{i=1}^{n} k_{8 i}\left[\mathrm{~B}_{\mathrm{pi}}\right]}}
\end{aligned}
$$

Introducing Eq. (A.1) into Eq. (A.2), the expression for the hole concentration is obtained:

$$
\left[\mathrm{h}^{+}\right]=\frac{k_{3}\left[\mathrm{O}_{2}\right]}{2 k_{2}}\left\{-1+\sqrt{1+\frac{4 k_{2} r_{g}}{k_{3} k_{4}\left[\mathrm{H}_{2} \mathrm{O}\right]\left[\mathrm{O}_{2}\right]}}\right\}
$$

Besides, the superficial rate of electron-hole generation is given by [30]:

$$
r_{g}(\mathbf{x})=\frac{\bar{\Phi}}{a_{v}} \int_{\lambda} e_{\lambda}^{a}(\mathbf{x}) \mathrm{d} \lambda=\frac{\bar{\Phi} e^{a}(\mathbf{x})}{S_{g} C_{c a t}}
$$

where $e^{a}(\mathbf{x})$ represents the local volumetric rate of photon absorption (LVRPA) and $\bar{\Phi}$ is the primary quantum yield averaged over the wavelength range.

Then, from Eqs. (A.3), (A.4) and (A.5), results

$$
[\cdot \mathrm{OH}]^{\ell}=\frac{\alpha_{1}^{\prime}}{k_{5}\left[\mathrm{~B}_{\mathrm{u}}\right]+k_{6}\left[\mathrm{~B}_{\mathrm{d}}\right]+k_{7}\left[\mathrm{~B}_{\mathrm{i}}\right]+\sum_{i=1}^{n} k_{8 i}\left[\mathrm{~B}_{\mathrm{pi}}\right]}\left\{-1+\sqrt{1+\frac{\alpha_{2} e^{a}}{S_{g} C_{c a t}}}\right\}
$$

where

$$
\alpha_{1}^{\prime}=\frac{k_{3} k_{4}\left[\mathrm{H}_{2} \mathrm{O}\right]\left[\mathrm{O}_{2}\right]}{2 \ell k_{2}} \quad \text { and } \quad \alpha_{2}=\frac{4 k_{2} \bar{\Phi}}{k_{3} k_{4}\left[\mathrm{H}_{2} \mathrm{O}\right]\left[\mathrm{O}_{2}\right]}
$$

Introducing Eq. (A.6) into the superficial rate expression for the undamaged bacteria (Table 1), we derive the following equation: 


$$
\begin{aligned}
r_{u}\left(\frac{\mathrm{CFU}}{\mathrm{s} \mathrm{cm}_{\mathrm{int}}^{2}}\right)=-k_{5}\left[\mathrm{~B}_{\mathrm{u}}\right][\cdot \mathrm{OH}]^{\ell}= & \\
& -\frac{\alpha_{1}^{\prime} k_{5}\left[\mathrm{~B}_{\mathrm{u}}\right]}{k_{5}\left[\mathrm{~B}_{\mathrm{u}}\right]+k_{6}\left[\mathrm{~B}_{\mathrm{d}}\right]+k_{7}\left[\mathrm{~B}_{\mathrm{i}}\right]+\sum_{i=1}^{n} k_{8 i}\left[\mathrm{~B}_{\mathrm{pi}}\right]}\left\{-1+\sqrt{1+\frac{\alpha_{2} e^{a}}{S_{g} C_{c a t}}}\right\}
\end{aligned}
$$

The superficial disappearance rate of undamaged bacteria $\left(r_{u}\right)$ can be transformed into the corresponding volumetric disappearance rate $\left(R_{u}\right)$ by the equation

$$
R_{u}\left(\frac{\mathrm{CFU}}{\mathrm{s} \mathrm{cm}^{3}}\right)=r_{u} a_{v, i n t}=r_{u} f_{i n t} a_{v}=r_{u} f_{\text {int }} S_{c e l} \mathrm{~B}_{\mathrm{u}}
$$

where $a_{v, \text { int }}$ is the bacteria-catalyst interacting surface area per unit suspension volume, $f_{\text {int }}$ the fraction of bacteria-catalyst interacting surface area, $a_{v}$ the total bacteria surface area per unit suspension volume, and $S_{c e l}$ the specific surface area of the bacterial cells.

The adsorption equilibrium between catalyst particles and a cell [11], can be expressed as

$$
K_{a d s}=\frac{C_{c a t, a d s}}{[\text { Site }]_{\text {vac }} C_{c a t, b u l k}}=\frac{C_{c a t, a d s}}{[\text { Site }]_{\mathrm{vac}} C_{c a t}}
$$

Considering that $[\text { Site }]_{\mathrm{Tot}},[\text { Site }]_{\mathrm{vac}}$ and $[\text { Site }]_{\mathrm{cat}}$ are the total, vacant and occupied sites on the external surface of the bacterial cell, we can write:

$[\text { Site }]_{\text {Tot }}=[\text { Site }]_{\mathrm{vac}}+[\text { Site }]_{\text {cat }}=[\text { Site }]_{\mathrm{vac}}+[\text { Site }]_{\mathrm{vac}} K_{a d s} C_{\text {cat }}=[\text { Site }]_{\mathrm{vac}} 1+K_{\text {ads }} C_{\text {cat }}$

Thus, the fraction of bacteria-catalyst interacting surface area is given by

$$
f_{\text {int }}\left(\frac{\mathrm{cm}_{\mathrm{int}}^{2}}{\mathrm{~cm}^{2}}\right)=1-f_{v a c}\left(\frac{\mathrm{cm}_{\mathrm{vac}}^{2}}{\mathrm{~cm}^{2}}\right)=1-\frac{1}{1+K_{a d s} C_{c a t}}=\frac{K_{a d s} C_{c a t}}{1+K_{a d s} C_{c a t}}
$$

Finally, from Eqs. (A.8), (A.9) and (A.12), we can write:

$$
R_{u}\left(\frac{\mathrm{CFU}}{\mathrm{s} \mathrm{cm}^{3}}\right)=-\alpha_{1}\left(\frac{K_{a d s} C_{c a t}}{1+K_{a d s} C_{c a t}}\right) \frac{k_{5}\left[\mathrm{~B}_{\mathrm{u}}\right]^{2}}{k_{5}\left[\mathrm{~B}_{\mathrm{u}}\right]+k_{6}\left[\mathrm{~B}_{\mathrm{d}}\right]+k_{7}\left[\mathrm{~B}_{\mathrm{i}}\right]+\bar{k}_{8}\left[\mathrm{~B}_{\mathrm{p}}\right]}\left[-1+\sqrt{1+\frac{\alpha_{2} e^{a}}{S_{g} C_{c a t}}}\right]
$$

where

$$
\begin{aligned}
& \alpha_{1}=\alpha_{1}^{\prime} S_{c e l} \\
& \bar{k}_{8}=\frac{\sum_{i=1}^{n} k_{8 i}\left[\mathrm{~B}_{\mathrm{pi}}\right]}{\sum_{i=1}^{n}\left[\mathrm{~B}_{\mathrm{pi}}\right]}=\frac{\sum_{i=1}^{n} k_{8 i}\left[\mathrm{~B}_{\mathrm{pi}}\right]}{\left[\mathrm{B}_{\mathrm{p}}\right]}
\end{aligned}
$$

Following the same procedure for the volumetric disappearance rate of damaged bacteria $\left(R_{d}\right)$, the following expression is obtained: 
$R_{d}\left(\frac{\mathrm{CFU}}{\mathrm{s} \mathrm{cm}^{3}}\right)=\alpha_{1}\left(\frac{K_{a d s} C_{c a t}}{1+K_{a d s} C_{c a t}}\right) \frac{k_{5}\left[\mathrm{~B}_{\mathrm{u}}\right]^{2}-k_{6}\left[\mathrm{~B}_{\mathrm{d}}\right]^{2}}{k_{5}\left[\mathrm{~B}_{\mathrm{u}}\right]+k_{6}\left[\mathrm{~B}_{\mathrm{d}}\right]+k_{7}\left[\mathrm{~B}_{\mathrm{i}}\right]+\bar{k}_{8}\left[\mathrm{~B}_{\mathrm{p}}\right]}\left[-1+\sqrt{1+\frac{\alpha_{2} e^{a}}{S_{g} C_{c a t}}}\right]$

Assuming that the bacterial lysis of the inactivated bacteria $\left[\mathrm{B}_{\mathrm{i}}\right]$ can generate $n$ molecules of organic compounds, $\left[\mathrm{B}_{\mathrm{p}}\right]$ is estimated by:

$\left[\mathrm{B}_{\mathrm{p}}\right]=\sum_{i=1}^{n}\left[\mathrm{~B}_{\mathrm{pi}}\right]=n\left[\mathrm{~B}_{\mathrm{i}}\right]=n[\mathrm{~B}]_{0}-\left[\mathrm{B}_{\mathrm{u}}\right]-\left[\mathrm{B}_{\mathrm{d}}\right]$

Substituting Eq. (A.17) into Eqs. (A.13) and (A.16), and rearranging the resulting equations, the final expressions for the volumetric disappearance rate of undamaged and damaged bacteria are obtained:

$$
\begin{aligned}
& R_{u}\left(\frac{\mathrm{CFU}}{\mathrm{s} \mathrm{cm}^{3}}\right)=-\alpha_{1}\left(\frac{K_{a d s} C_{c a t}}{1+K_{a d s} C_{c a t}}\right) \frac{\left[\mathrm{B}_{\mathrm{u}}\right]^{2}}{\left[\mathrm{~B}_{\mathrm{u}}\right]+\alpha_{4}\left[\mathrm{~B}_{\mathrm{d}}\right]+\alpha_{3}[\mathrm{~B}]_{0}-\left[\mathrm{B}_{\mathrm{u}}\right]-\left[\mathrm{B}_{\mathrm{d}}\right]}\left[-1+\sqrt{1+\frac{\alpha_{2} e^{a}}{S_{g} C_{c a t}}}\right] \\
& R_{d}\left(\frac{\mathrm{CFU}}{\mathrm{s} \mathrm{cm}^{3}}\right)=\alpha_{1}\left(\frac{K_{a d s} C_{c a t}}{1+K_{a d s} C_{c a t}}\right) \frac{\left[\mathrm{B}_{\mathrm{u}}\right]^{2}-\alpha_{4}\left[\mathrm{~B}_{\mathrm{d}}\right]^{2}}{\left[\mathrm{~B}_{\mathrm{u}}\right]+\alpha_{4}\left[\mathrm{~B}_{\mathrm{d}}\right]+\alpha_{3}[\mathrm{~B}]_{0}-\left[\mathrm{B}_{\mathrm{u}}\right]-\left[\mathrm{B}_{\mathrm{d}}\right]}\left[-1+\sqrt{1+\frac{\alpha_{2} e^{a}}{S_{g} C_{c a t}}}\right]
\end{aligned}
$$

where

$$
\alpha_{3}=\left(\frac{k_{7}+\bar{k}_{8} n}{k_{5}}\right) \quad \text { and } \quad \alpha_{4}=\frac{k_{6}}{k_{5}}
$$

\section{Limiting cases}

Case I: $K_{a d s} C_{c a t}<<1$

Equations (A.18) and (A.19) will take the form

$$
\begin{aligned}
& R_{u}\left(\frac{\mathrm{CFU}}{\mathrm{s} \mathrm{cm}^{3}}\right)=-\alpha C_{c a t} \frac{\left[\mathrm{B}_{\mathrm{u}}\right]^{2}}{\left[\mathrm{~B}_{\mathrm{u}}\right]+\alpha_{4}\left[\mathrm{~B}_{\mathrm{d}}\right]+\alpha_{3}[\mathrm{~B}]_{0}-\left[\mathrm{B}_{\mathrm{u}}\right]-\left[\mathrm{B}_{\mathrm{d}}\right]}\left[-1+\sqrt{1+\frac{\alpha_{2} e^{a}}{S_{g} C_{c a t}}}\right] \\
& R_{d}\left(\frac{\mathrm{CFU}}{\mathrm{s} \mathrm{cm}^{3}}\right)=\alpha C_{c a t} \frac{\left[\mathrm{B}_{\mathrm{u}}\right]^{2}-\alpha_{4}\left[\mathrm{~B}_{\mathrm{d}}\right]^{2}}{\left[\mathrm{~B}_{\mathrm{u}}\right]+\alpha_{4}\left[\mathrm{~B}_{\mathrm{d}}\right]+\alpha_{3}[\mathrm{~B}]_{0}-\left[\mathrm{B}_{\mathrm{u}}\right]-\left[\mathrm{B}_{\mathrm{d}}\right]}\left[-1+\sqrt{1+\frac{\alpha_{2} e^{a}}{S_{g} C_{c a t}}}\right]
\end{aligned}
$$

where $\alpha=\alpha_{1} K_{a d s}$

Subcase I.a: $\frac{\alpha_{2} e^{a}}{S_{g} C_{c a t}}<<1$

Under this condition, and taken the first term of the square root Taylor expansion, Eqs. (A.21) and (A.22) will take the form

$$
R_{u}\left(\frac{\mathrm{CFU}}{\mathrm{s} \mathrm{cm}^{3}}\right)=-\alpha \frac{1}{S_{g}} \frac{\left[\mathrm{B}_{\mathrm{u}}\right]^{2}}{\left[\mathrm{~B}_{\mathrm{u}}\right]+\alpha_{4}\left[\mathrm{~B}_{\mathrm{d}}\right]+\alpha_{3}[\mathrm{~B}]_{0}-\left[\mathrm{B}_{\mathrm{u}}\right]-\left[\mathrm{B}_{\mathrm{d}}\right]} e^{a}
$$


$R_{d}\left(\frac{\mathrm{CFU}}{\mathrm{s} \mathrm{cm}^{3}}\right)=\alpha \frac{1}{S_{g}} \frac{\left[\mathrm{B}_{\mathrm{u}}\right]^{2}-\alpha_{4}\left[\mathrm{~B}_{\mathrm{d}}\right]^{2}}{\left[\mathrm{~B}_{\mathrm{u}}\right]+\alpha_{4}\left[\mathrm{~B}_{\mathrm{d}}\right]+\alpha_{3}[\mathrm{~B}]_{0}-\left[\mathrm{B}_{\mathrm{u}}\right]-\left[\mathrm{B}_{\mathrm{d}}\right]} e^{a}$

where $\alpha=\frac{\alpha_{1} \alpha_{2} K_{a d s}}{2}$

Subcase I.b: $\frac{\alpha_{2} e^{a}}{S_{g} C_{c a t}}>>1$

Under this condition, Eqs. (A.21) and (A.22) will take the form

$$
\begin{aligned}
& R_{u}\left(\frac{\mathrm{CFU}}{\mathrm{s} \mathrm{cm}^{3}}\right)=-\alpha \sqrt{\frac{C_{c a t}}{S_{g}}} \frac{\left[\mathrm{B}_{\mathrm{u}}\right]^{2}}{\left[\mathrm{~B}_{\mathrm{u}}\right]+\alpha_{4}\left[\mathrm{~B}_{\mathrm{d}}\right]+\alpha_{3}[\mathrm{~B}]_{0}-\left[\mathrm{B}_{\mathrm{u}}\right]-\left[\mathrm{B}_{\mathrm{d}}\right]} \sqrt{e^{a}} \\
& R_{d}\left(\frac{\mathrm{CFU}}{\mathrm{s} \mathrm{cm}^{3}}\right)=\alpha \sqrt{\frac{C_{c a t}}{S_{g}}} \frac{\left[\mathrm{B}_{\mathrm{u}}\right]^{2}-\alpha_{4}\left[\mathrm{~B}_{\mathrm{d}}\right]^{2}}{\left[\mathrm{~B}_{\mathrm{u}}\right]+\alpha_{4}\left[\mathrm{~B}_{\mathrm{d}}\right]+\alpha_{3}[\mathrm{~B}]_{0}-\left[\mathrm{B}_{\mathrm{u}}\right]-\left[\mathrm{B}_{\mathrm{d}}\right]} \sqrt{e^{a}}
\end{aligned}
$$

where $\alpha=\alpha_{1} \sqrt{\alpha_{2}} K_{a d s}$

Case II: $K_{a d s} C_{c a t}>>1$

Equations (A.18) and (A.19) will take the form

$$
\begin{aligned}
& R_{u}\left(\frac{\mathrm{CFU}}{\mathrm{s} \mathrm{cm}^{3}}\right)=-\alpha_{1} \frac{\left[\mathrm{B}_{\mathrm{u}}\right]^{2}}{\left[\mathrm{~B}_{\mathrm{u}}\right]+\alpha_{4}\left[\mathrm{~B}_{\mathrm{d}}\right]+\alpha_{3}[\mathrm{~B}]_{0}-\left[\mathrm{B}_{\mathrm{u}}\right]-\left[\mathrm{B}_{\mathrm{d}}\right]}\left[-1+\sqrt{1+\frac{\alpha_{2} e^{a}}{S_{g} C_{c a t}}}\right] \\
& R_{d}\left(\frac{\mathrm{CFU}}{\mathrm{s} \mathrm{cm}^{3}}\right)=\alpha_{1} \frac{\left[\mathrm{B}_{\mathrm{u}}\right]^{2}-\alpha_{4}\left[\mathrm{~B}_{\mathrm{d}}\right]^{2}}{\left[\mathrm{~B}_{\mathrm{u}}\right]+\alpha_{4}\left[\mathrm{~B}_{\mathrm{d}}\right]+\alpha_{3}[\mathrm{~B}]_{0}-\left[\mathrm{B}_{\mathrm{u}}\right]-\left[\mathrm{B}_{\mathrm{d}}\right]}\left[-1+\sqrt{1+\frac{\alpha_{2} e^{a}}{S_{g} C_{c a t}}}\right]
\end{aligned}
$$

Subcase II.a: $\frac{\alpha_{2} e^{a}}{S_{g} C_{c a t}}<<1$

Under this condition, Eqs. (A.27) and (A.28) will take the form

$$
\begin{aligned}
& R_{u}\left(\frac{\mathrm{CFU}}{\mathrm{s} \mathrm{cm}^{3}}\right)=-\alpha \frac{1}{S_{g} C_{c a t}} \frac{\left[\mathrm{B}_{\mathrm{u}}\right]+\alpha_{4}\left[\mathrm{~B}_{\mathrm{d}}\right]+\alpha_{3}[\mathrm{~B}]_{0}-\left[\mathrm{B}_{\mathrm{u}}\right]-\left[\mathrm{B}_{\mathrm{d}}\right]}{e^{a}} \\
& R_{d}\left(\frac{\mathrm{CFU}}{\mathrm{s} \mathrm{cm}^{3}}\right)=\alpha \frac{1}{S_{g} C_{c a t}} \frac{\left.\left[\mathrm{B}_{\mathrm{u}}\right]^{2}-\alpha_{4}\left[\mathrm{~B}_{\mathrm{d}}\right]^{2}\right]+\alpha_{4}\left[\mathrm{~B}_{\mathrm{d}}\right]+\alpha_{3}[\mathrm{~B}]_{0}-\left[\mathrm{B}_{\mathrm{u}}\right]-\left[\mathrm{B}_{\mathrm{d}}\right]}{\left[\mathrm{B}^{a}\right.}
\end{aligned}
$$

where $\alpha=\frac{\alpha_{1} \alpha_{2}}{2}$

Subcase II.b: $\frac{\alpha_{2} e^{a}}{S_{g} C_{c a t}}>>1$ 
Under this condition, Eqs. (A.27) and (A.28) will take the form

$$
\begin{aligned}
& R_{u}\left(\frac{\mathrm{CFU}}{\mathrm{s} \mathrm{cm}^{3}}\right)=-\alpha \sqrt{\frac{1}{S_{g} C_{c a t}}} \frac{\left[\mathrm{B}_{\mathrm{u}}\right]^{2}}{\left[\mathrm{~B}_{\mathrm{u}}\right]+\alpha_{4}\left[\mathrm{~B}_{\mathrm{d}}\right]+\alpha_{3}[\mathrm{~B}]_{0}-\left[\mathrm{B}_{\mathrm{u}}\right]-\left[\mathrm{B}_{\mathrm{d}}\right]} \sqrt{e^{a}} \\
& R_{d}\left(\frac{\mathrm{CFU}}{\mathrm{s} \mathrm{cm}^{3}}\right)=\alpha \sqrt{\frac{1}{S_{g} C_{c a t}}} \frac{\left[\mathrm{B}_{\mathrm{u}}\right]^{2}-\alpha_{4}\left[\mathrm{~B}_{\mathrm{d}}\right]^{2}}{\left[\mathrm{~B}_{\mathrm{u}}\right]+\alpha_{4}\left[\mathrm{~B}_{\mathrm{d}}\right]+\alpha_{3}[\mathrm{~B}]_{0}-\left[\mathrm{B}_{\mathrm{u}}\right]-\left[\mathrm{B}_{\mathrm{d}}\right]} \sqrt{e^{a}}
\end{aligned}
$$

where $\alpha=\alpha_{1} \sqrt{\alpha_{2}}$ 
Appendix B. Distribution of the fitting residuals for the different kinetic models.

FIGURE B1

FIGURE B2

FIGURE B3 


\section{Nomenclature}

\begin{tabular}{|c|c|}
\hline$a_{v}$ & catalyst surface area per unit volume, $\mathrm{cm}^{-1}$ \\
\hline$a_{v, \text { int }}$ & bacteria-catalyst interacting surface area per unit volume, $\mathrm{cm}^{-1}$ \\
\hline B & bacteria \\
\hline$C$ & bacteria concentration, $\mathrm{CFU} \mathrm{cm}{ }^{-3}$ \\
\hline$C_{c a t}$ & catalyst mass concentration, $\mathrm{g} \mathrm{cm}^{-3}$ \\
\hline$e^{a}$ & local volumetric rate of photon absorption, Einstein $\mathrm{cm}^{-3} \mathrm{~s}^{-1}$ \\
\hline$f$ & fraction of bacteria-catalyst surface area, dimensionless \\
\hline$I$ & radiation intensity, Einstein $\mathrm{cm}^{-2} \mathrm{~s}^{-1} \mathrm{sr}^{-1}$ \\
\hline$k$ & kinetic constant, $\mathrm{cm}^{2} \mathrm{~mol}^{-1} \mathrm{~s}^{-1}$ \\
\hline$K_{a d s}$ & equilibrium adsorption constant, $\mathrm{cm}^{3} \mathrm{~g}^{-1}$ \\
\hline$\ell$ & stoichiometric coefficient \\
\hline NRMSLE & normalized root mean square logarithmic error, $\%$ \\
\hline$P^{0}$ & irradiation power, Einstein $\mathrm{s}^{-1}$ \\
\hline$r_{g}$ & superficial rate of electron-hole generation, $\mathrm{mol} \mathrm{cm} \mathrm{cm}^{-2} \mathrm{~s}^{-1}$ \\
\hline$r$ & superficial reaction rate for bacteria, $\mathrm{CFU} \mathrm{cm} \mathrm{cm}^{-2} \mathrm{~s}^{-1}$ \\
\hline$R$ & volumetric reaction rate for bacteria, $\mathrm{CFU} \mathrm{cm} \mathrm{cm}^{-3} \mathrm{~s}^{-1}$ \\
\hline$S_{c e l}$ & specific surface area of the bacterial cells, $\mathrm{cm}^{2} \mathrm{~g}^{-1}$ \\
\hline$S_{g}$ & specific surface area of the catalyst, $\mathrm{cm}^{2} \mathrm{~g}^{-1}$ \\
\hline & time, $\mathrm{s}$ \\
\hline$V$ & volume, $\mathrm{cm}^{3}$ \\
\hline & position vector in a $3 \mathrm{D}$ space, $\mathrm{cm}$ \\
\hline
\end{tabular}

Greek letters

$\alpha$

$\alpha_{1}$

$\alpha_{2}$

$\alpha_{3}$

$\alpha_{4}$

$\bar{\Phi}$

$\kappa$

$\lambda$

kinetic parameter, units depend on the specific kinetic model kinetic parameter, $\mathrm{s}^{-1}$

kinetic parameter, $\mathrm{cm}^{2} \mathrm{~s}$ Einstein ${ }^{-1}$

kinetic parameter, dimensionless

kinetic parameter, dimensionless

wavelength averaged primary quantum yield, mol Einstein $^{-1}$

napierian volumetric absorption coefficient, $\mathrm{cm}^{-1}$

wavelength, $\mathrm{nm}$ 
$v_{i} \quad$ stoichiometric coefficient

$\Omega \quad$ solid angle of radiation propagation about the direction $\underline{\Omega}, \mathrm{sr}$

$\underline{\Omega} \quad$ unit vector in the direction of radiation propagation

$\begin{array}{ll}\text { Subscripts } & \\ 0 & \text { indicates initial condition } \\ \text { ads } & \text { relative to the adsorbed phase } \\ \text { bulk } & \text { relative to the bulk suspension } \\ \text { cat } & \text { relative to the catalyst } \\ \text { d } & \text { relative to damaged bacteria } \\ \text { i } & \text { relative to inactivated bacteria } \\ \text { int } & \text { relative to bacteria-catalyst interacting surface } \\ \text { p } & \text { relative to products of bacteria lysis } \\ \text { pi } & \text { relative to products of bacteria lysis } \\ \text { Reactor } & \text { relative to the reactor } \\ \text { tot } & \text { relative to the total surface / sites of the catalyst / bacteria } \\ \text { Total } & \text { relative to the total recirculating system } \\ \text { Tank } & \text { relative to the reservoir tank } \\ \mathrm{u} & \text { relative to undamaged bacteria } \\ \text { vac } & \text { relative to vacant surface / sites of the catalyst / bacteria } \\ \mathrm{V}_{\text {React }} & \begin{array}{l}\text { relative to the reactor volume } \\ \lambda\end{array} \\ \underline{\text { indicates a dependence on wavelength }} \\ \text { indicates a directional dependence }\end{array}$

Superscripts

Calc calculated value

Exp experimental value

Special symbols

indicates a vectorial magnitude
concentration of chemical species on the catalyst surface, $\mathrm{mol} \mathrm{cm}^{-2}$, or
concentration of bacteria species in the bulk, CFU cm
\langle\rangle$\quad$ indicates average value 


\section{References}

[1] C. McCullagh, J.M.C. Robertson, D.W. Bahnemann, P.K.J. Robertson, Res. Chem. Intermediat. 33 (2007) 359-375.

[2] S. Malato, P. Fernández-Ibáñez, M.I. Maldonado, J. Blanco, W. Gernjak, Catal. Today 147 (2009) 1-59.

[3] M.N. Chong, B. Jin, C.W.K. Chow, C. Saint, Water Res. 44 (2010) 2997-3027.

[4] K. Gopal, S.S. Tripathy, J.L. Bersillon, S.P. Dubey, J. Hazard. Mater. 140 (2007) 1-6.

[5] U. von Gunten, Water Res. 37 (2003) 1469-1487.

[6] I. Muñoz, J. Rieradevall, F. Torrades, J. Peral, X. Domènech, Sol. Energy 79 (2005) 369-375.

[7] M. Otaki, T. Hirata, S. Ohgaki, Water Sci. Technol. 42 (2000) 103-108.

[8] C. Guillard, T.H. Bui, C. Felix, V. Moules, B. Lina, P. Lejeune, Comptes Rendus Chimie 11 (2008) 107-113.

[9] J.R. Peller, R.L. Whitman, S. Griffith, P. Harris, C. Peller, J. Scalzitti, J. Photochem. Photobiol. A: Chem. 186 (2007) 212-217.

[10] C. Sichel, M. de Cara, J. Tello, J. Blanco, P. Fernández-Ibáñez, Appl. Catal. B: Environ. (2007) 152-160.

[11] Y. Horie, D.A. David, M. Taya, S. Tone, Ind. Eng. Chem. Res. 35 (1996) 3920-3926.

[12] F. Méndez-Hermida, E. Ares-Mazas, K.G. McGuigan, M. Boyle, C. Sichel P. Fernández-Ibáñez, J. Photochem. Photobiol. A:Chem. 88 (2007) 105-111.

[13] O. Sunnotel, R. Verdoold, P.S.M. Dunlop, W.J. Snelling, C.J. Lowery, J.S.G. Dooley, J.E. Moore, J.A. Byrne, J. Water Health 8 (2010) 83-91.

[14] A.K. Benabbou, Z. Derriche, C. Felix, P. Lejeune, C. Guillard C., Appl. Catal. B: Environ. 76 (2007) 257-263.

[15] J. Marugán, R. van Grieken, C. Pablos, C. Sordo, Water Res. 44 (2010) 789-796.

[16] P. Fernández, J. Blanco, C. Sichel, S. Malato, Catal. Today 101 (2005) 345-352.

[17] A.G. Rincón, C. Pulgarín, Appl. Catal. B: Environ. 63 (2006) 222-231.

[18] R. van Grieken, J. Marugán, C. Sordo, C. Pablos, Catal. Today 144 (2009) 48-54.

[19] D.M.A. Alrousan, P.S.M. Dunlop, T.A. McMurray, J.A. Byrne, Water Res. 43 (2009) 47-54.

[20] A. Kubacka, M. Ferrer, A. Martínez-Arias, M. Fernández-García, Appl. Catal. B: Environ. 84 (2008) 87-93. 
[21] R. van Grieken, J. Marugán, C. Sordo, P. Martínez, C. Pablos, Appl. Catal. B: Environ. 93 (2009) 112-118.

[22] A.G. Rincón, C. Pulgarín, Appl. Catal. B: Environ. 51 (2004) 283-302.

[23] J. Marugán, R. van Grieken, C. Sordo, C. Cruz, Appl. Catal. B: Environ. 82 (2008) 27-36. Corrigendum: Appl. Catal. B: Environ. 88 (2009) 582-583.

[24] L. Rizzo, J. Hazard. Mater. 165 (2009) 48-51.

[25] J.A. Herrera Melián, J.M. Doña Rodríguez, A. Viera Suárez, E. Tello Rendón, C. Valdés do Campo, J. Araña, J. Pérez Peña, Chemosphere 41 (2000) 323-327.

[26] O.K. Dalrymple, E. Stefanakos, M.A. Trotz, D.Y. Goswami, Appl. Catal. B: Environ. (2010), doi:10.1016/j.apcatb.2010.05.001

[27] L. Vincze, T.J. Kemp., J. Photochem. Photobiol. A:Chem. 87 (1995) 257-260.

[28] L. Rideh, A. Wehrer, D. Ronze, A. Zoulalian, Ind. Eng. Chem. Res. 36 (1997) $4712-$ 4718.

[29] A. Mills, J. Wang, D.F. Ollis, J. Catal. 243 (2006) 1-6.

[30] O.M. Alfano, M.I. Cabrera, A.E. Cassano, J. Catal. 172 (1997) 370-379.

[31] C.S. Zalazar, R.L. Romero, C.A. Martín, A.E. Cassano, Chem. Eng. Sci. 60 (2005) $5240-5254$.

[32] H. de Lasa, B. Serrano, M. Salaices, Photocatalytic Reaction Engineering, Springer, Berlin, Germany, 2005.

[33] B. Bayarri, J. Giménez, D. Curcó, S. Esplugas, Catal. Today 101 (2005) 227-236.

[34] M. Rodríguez, S. Malato, C. Pulgarin, S. Contreras, D. Curcó, J. Giménez, S. Esplugas, Solar Energy 79 (2005) 360-368.

[35] B. Toepfer, A. Gora, G. Li Puma, Appl. Catal. B:Environ. 68 (2006) 171-180.

[36] I. Salvado-Estivill, D.M Hargreaves, G. Li Puma, Environ. Sci. Technol. 41 (2007) 2028-2035.

[37] G. Camera-Roda, F. Santarelli, F. Catal. Today 129 (2007) 161-168.

[38] G. Camera-Roda, F. Santarelli, M. Panico, Photochem. Photobiol. Sci. 8 (2009) $712-$ 718.

[39] M.L. Satuf, R.J. Brandi, A.E. Cassano, O.M. Alfano, Catal. Today 129 (2007) 110117.

[40] J. Marugán, R. van Grieken, A.E. Cassano, O.M. Alfano, Appl. Catal. B: Environ. 85 (2008) 48-60.

[41] M. Cho, H. Chung, W. Choi, J. Yoon, Water Res. 38 (2004) 1069-1077. 
[42] F. Chen, X. Yang, F. Xu, W. Wu, Y. Zhang, Environ. Sci. Technol. 43 (2009) 11801184.

[43] J. Marugán, R. van Grieken, A.E. Cassano, O.M. Alfano, Water Sci. Technol. 61 (2010) 1547-1553.

[44] M.L. Satuf, R.J. Brandi, A.E. Cassano, O.M. Alfano, Ind. Eng. Chem. Res. 44 (2005) 6643-6649.

[45] J. Marugán, R. van Grieken, O.M. Alfano, A.E. Cassano, AIChE J. 52 (2006) 28322843.

[46] A.E. Cassano, C.A. Martin, R.J. Brandi and O.M. Alfano, Ind. Eng. Chem. Res. 34 (1995) 2155.

[47] J. Marugán, R. van Grieken, A.E. Cassano, O.M. Alfano, Catal. Today 144 (2009) 8793. 


\section{Figure Captions}

Figure 1. Schematic representation of the experimental photoreactor setup (see text for details).

Figure 2. Total irradiation power and spectral distribution of the unfiltered and filtered radiation entering the photoreactor, in comparison with the spectral distribution of the volumetric absorption coefficient of a Degussa $\mathrm{P} 25 \mathrm{TiO}_{2}$ suspension at natural $\mathrm{pH}$.

Figure 3. Reaction pathway proposed for the photocatalytic inactivation of bacteria.

Figure 4. Conceptual flowchart of the procedure for estimating the intrinsic kinetic parameters.

Figure 5. Experimental results (symbols) and simulation with the 5-parameters kinetic model represented by Eqs. (1) and (2) (lines).

Figure 6. Experimental results (symbols) and simulation with the 4-parameters kinetic model represented by Eqs. (8) and (9) (lines).

Figure 7. Experimental results (symbols) and simulation with the low irradiation flux 3parameters kinetic model represented by Eqs. (12) and (13) (lines).

Figure 8. Experimental results (symbols) and simulation with the high irradiation flux 3parameters kinetic model represented by Eqs. (14) and (15) (lines).

Figure B1. Distribution of the residuals for the 4-parameter kinetic model represented by Eqs. (8) and (9).

Figure B2. Distribution of the residuals for the 3-parameter kinetic model represented by Eqs. (12) and (13).

Figure B3. Distribution of the residuals for the 3-parameter kinetic model represented by Eqs. (14) and (15). 
Table 1. Proposed reaction scheme for the photocatalytic inactivation of bacteria, based on a hydroxyl radical generation photocatalytic reaction scheme [30] and a series-event disinfection mechanism [23].

\begin{tabular}{lll}
\hline STEP & REACTION & RATE \\
\hline Activation & $\mathrm{TiO}_{2} \stackrel{\mathrm{h} v}{\longrightarrow} \mathrm{TiO}_{2}+\mathrm{e}^{-}+\mathrm{h}^{+}$ & $r_{g}$ \\
Recombination & $\mathrm{e}^{-}+\mathrm{h}^{+} \rightarrow$ heat & $v_{\mathrm{i}} k_{2}\left[\mathrm{e}^{-}\right]\left[\mathrm{h}^{+}\right]$ \\
Electron trapping & $\mathrm{e}^{-}+\mathrm{O}_{2} \rightarrow \cdot \mathrm{O}_{2}^{-}$ & $v_{\mathrm{i}} k_{3}\left[\mathrm{e}^{-}\right]\left[\mathrm{O}_{2}\right]$ \\
Hole trapping & $\mathrm{h}^{+}+\mathrm{H}_{2} \mathrm{O} \rightarrow \cdot \mathrm{OH}+\mathrm{H}^{+}$ & $v_{\mathrm{i}} k_{4}\left[\mathrm{~h}^{+}\right]\left[\mathrm{H}_{2} \mathrm{O}\right]$ \\
Hydroxyl attack & $\mathrm{B}_{\mathrm{u}}+\ell \cdot \mathrm{OH} \rightarrow \mathrm{B}_{\mathrm{d}}$ & $v_{i} k_{5}[\cdot \mathrm{OH}]^{\ell}\left[\mathrm{B}_{\mathrm{u}}\right]$ \\
& $\mathrm{B}_{\mathrm{d}}+\ell \cdot \mathrm{OH} \rightarrow \mathrm{B}_{\mathrm{i}}$ & $v_{i} k_{6}[\cdot \mathrm{OH}]^{\ell}\left[\mathrm{B}_{\mathrm{d}}\right]$ \\
& $\mathrm{B}_{\mathrm{i}}+\ell \cdot \mathrm{OH} \rightarrow \mathrm{B}_{\mathrm{p} 1}+\mathrm{B}_{\mathrm{p} 2}+\ldots \mathrm{B}_{\mathrm{pi}} \ldots+\mathrm{B}_{\mathrm{pn}}$ & $v_{i} k_{7}[\cdot \mathrm{OH}]^{\ell}\left[\mathrm{B}_{\mathrm{i}}\right]$ \\
& $\mathrm{B}_{\mathrm{p} 1}+\ell \cdot \mathrm{OH} \rightarrow$ Products & $v_{i} k_{81}[\cdot \mathrm{OH}]^{\ell}\left[\mathrm{B}_{\mathrm{p} 1}\right]$ \\
& $\mathrm{B}_{\mathrm{p} 2}+\ell \cdot \mathrm{OH} \rightarrow$ Products & $v_{i} k_{82}[\cdot \mathrm{OH}]^{\ell}\left[\mathrm{B}_{\mathrm{p} 2}\right]$ \\
& $\ldots$ & $\cdots$ \\
& $\mathrm{B}_{\mathrm{pi}}+\ell \cdot \mathrm{OH} \rightarrow$ Products & $v_{i} k_{8 i}[\cdot \mathrm{OH}]^{\ell}\left[\mathrm{B}_{\mathrm{pi}}\right]$ \\
& $\ldots$ & $\cdots$ \\
Adsorption & $\mathrm{B}_{\mathrm{pn}}+\ell \cdot \mathrm{OH} \rightarrow$ Products & $v_{i} k_{8 n}[\cdot \mathrm{OH}]^{\ell}\left[\mathrm{B}_{\mathrm{pn}}\right]$ \\
\hline
\end{tabular}




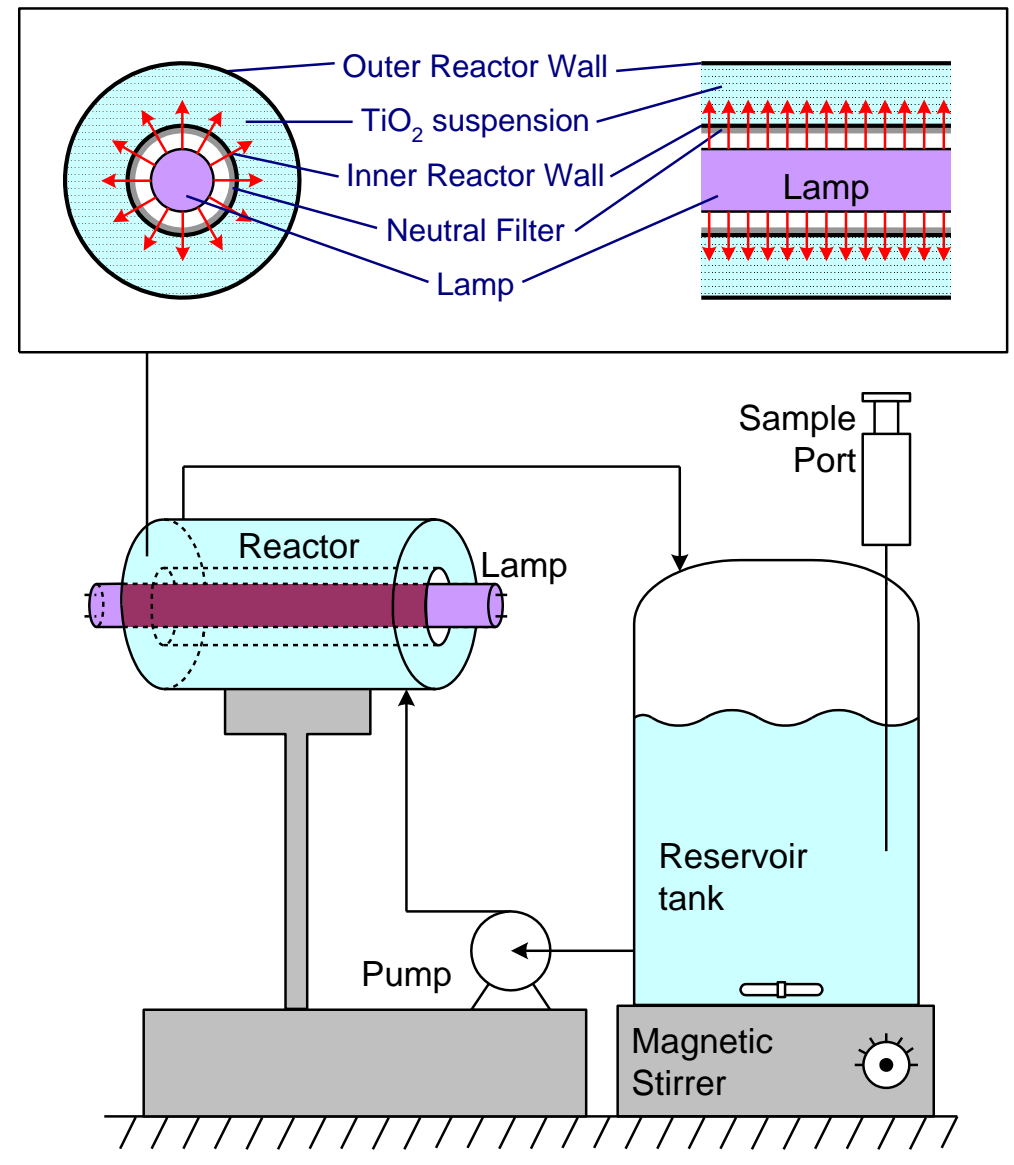

Figure 1. Schematic representation of the experimental photoreactor setup (see text for details). 


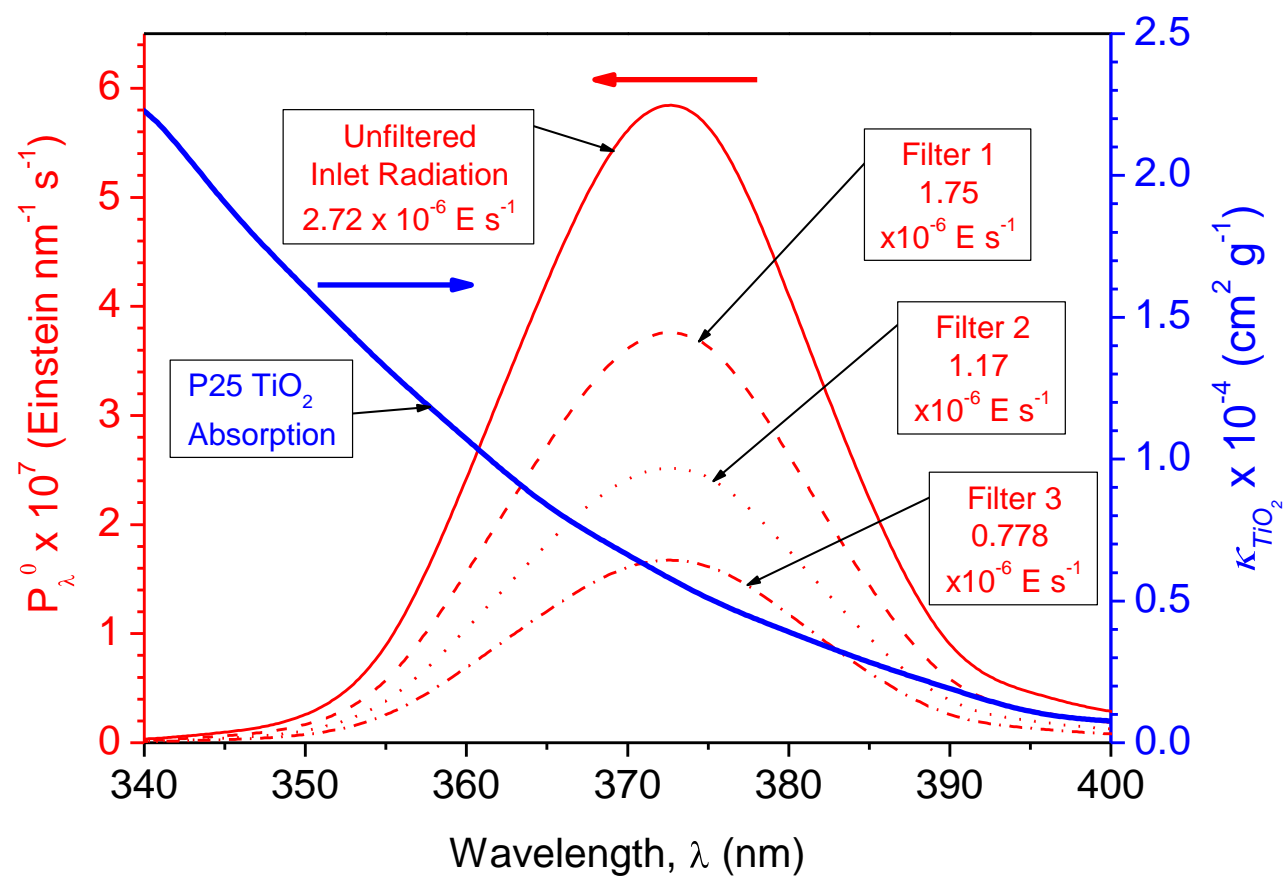

Figure 2. Total irradiation power and spectral distribution of the unfiltered and filtered radiation entering the photoreactor, in comparison with the spectral distribution of the volumetric absorption coefficient of a Degussa $\mathrm{P} 25 \mathrm{TiO}_{2}$ suspension at natural $\mathrm{pH}$. 


$$
\mathrm{B}_{\mathrm{u}} \stackrel{k_{5}}{\longrightarrow} \mathrm{B}_{\mathrm{d}} \stackrel{k_{6}}{\longrightarrow} \mathrm{B}_{\mathrm{i}} \stackrel{k_{7}}{\longrightarrow}\left\{\begin{array}{l}
\mathrm{B}_{\mathrm{p} 1} \stackrel{k_{81}}{\longrightarrow} \\
\mathrm{B}_{\mathrm{p} 2} \stackrel{k_{82}}{\longrightarrow} \\
\ldots \\
\mathrm{B}_{\mathrm{pi}} \stackrel{k_{8 i}}{\longrightarrow} \\
\ldots \\
\mathrm{B}_{\mathrm{pn}} \stackrel{k_{8 n}}{\longrightarrow}
\end{array}\right\} \text { Products }
$$

Figure 3. Reaction pathway proposed for the photocatalytic inactivation of bacteria. 


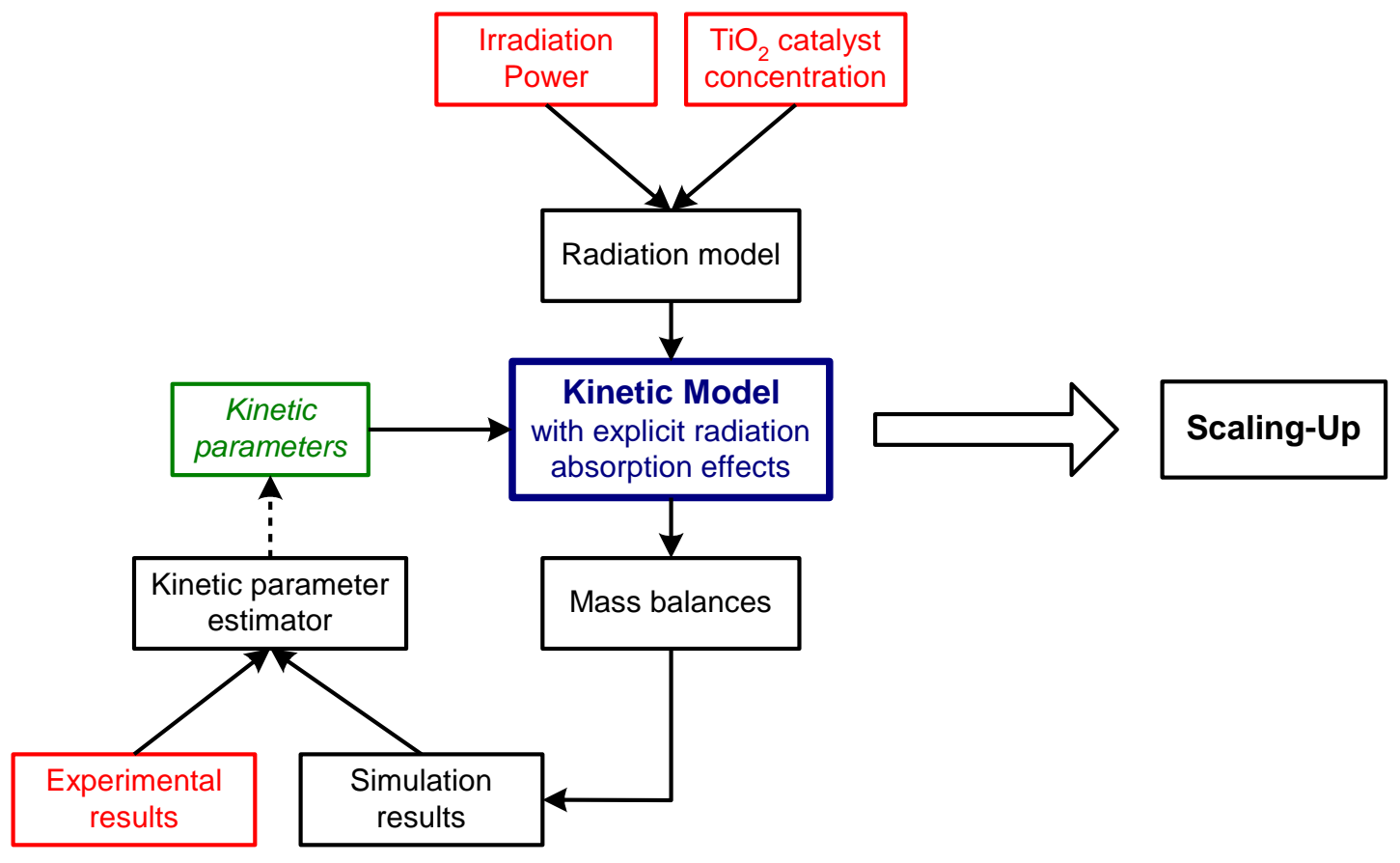

Figure 4. Conceptual flowchart of the procedure for estimating the intrinsic kinetic parameters. 

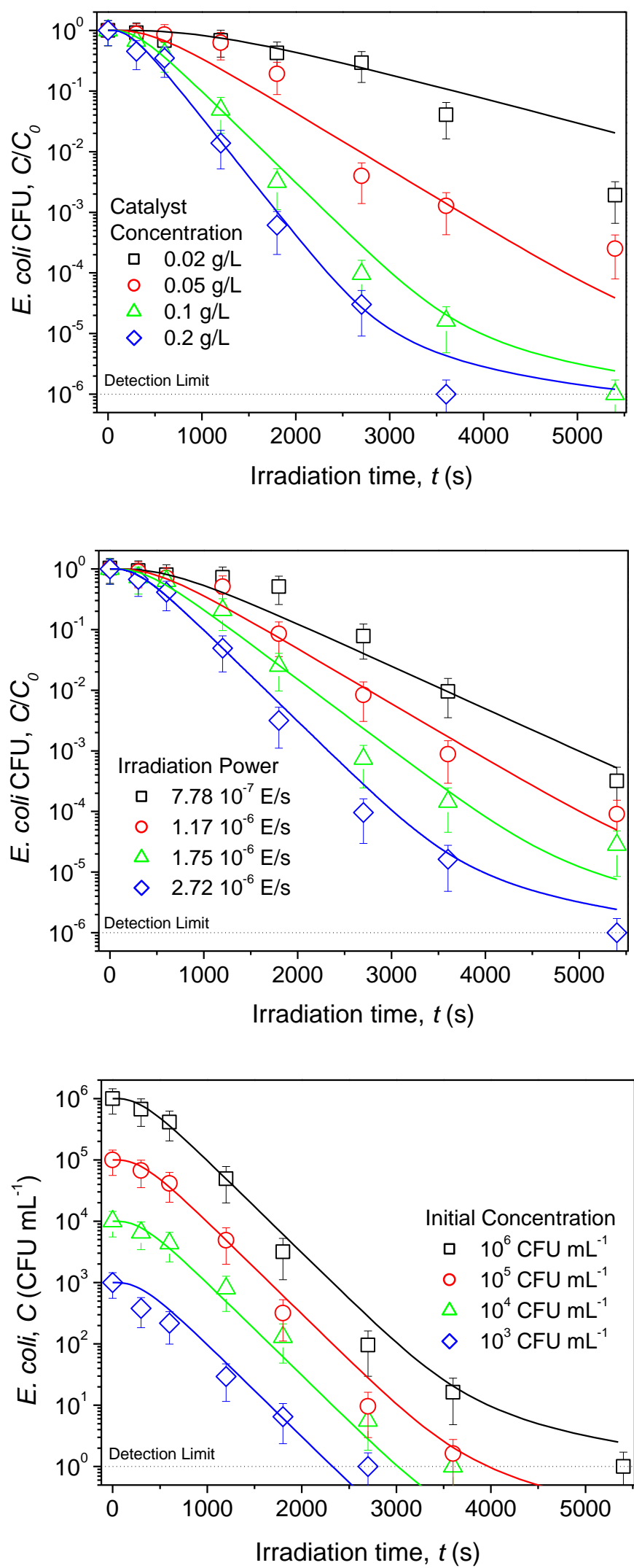

Figure 5. Experimental results (symbols) and simulation with the 5-parameter kinetic model represented by Eqs. (1) and (2) (lines). 

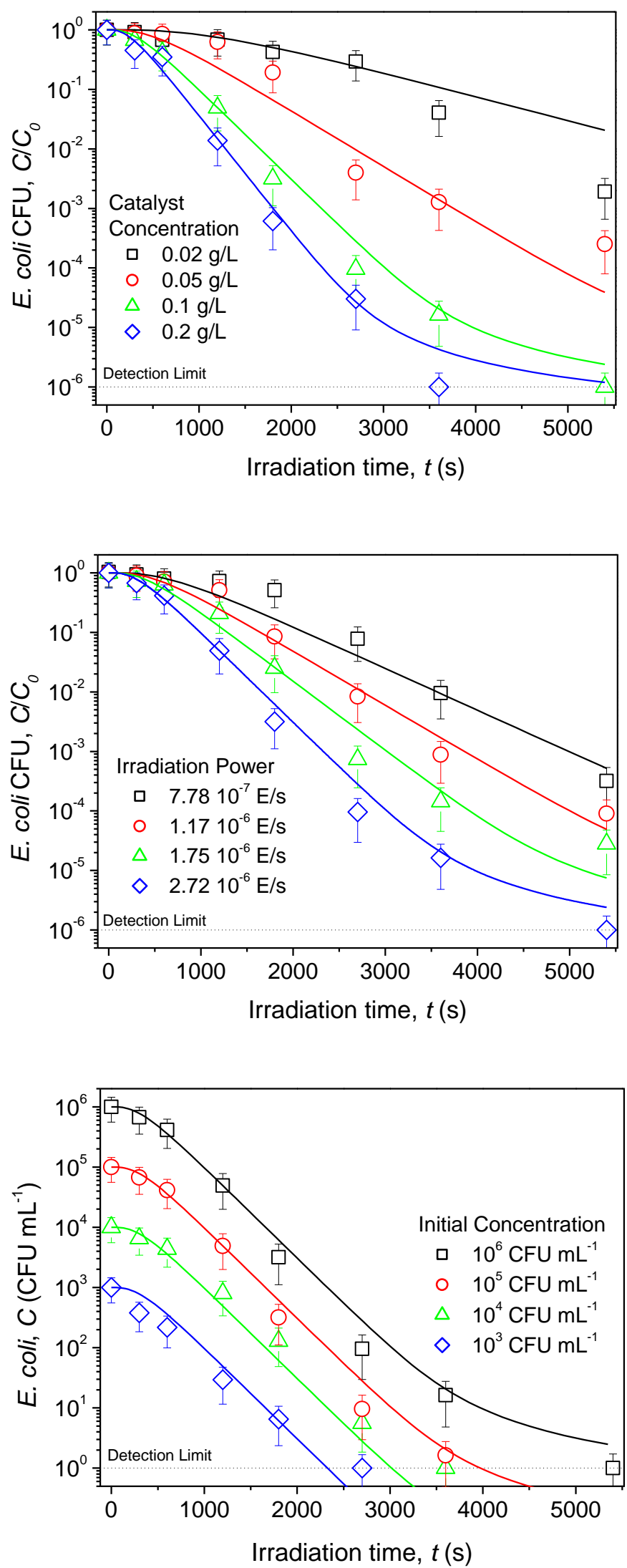

Figure 6. Experimental results (symbols) and simulation with the 4-parameter kinetic model represented by Eqs. (8) and (9) (lines). 

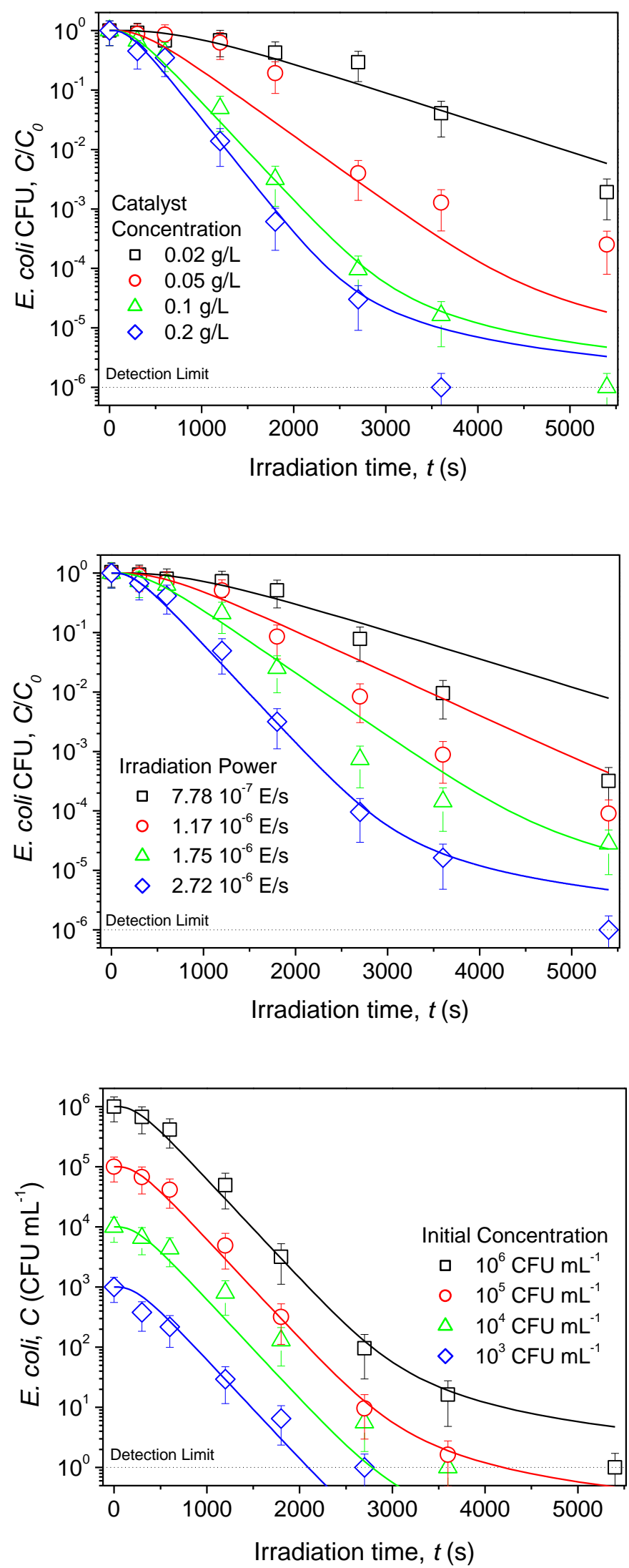

Figure 7. Experimental results (symbols) and simulation with the low irradiation flux 3parameter kinetic model represented by Eqs. (12) and (13) (lines). 

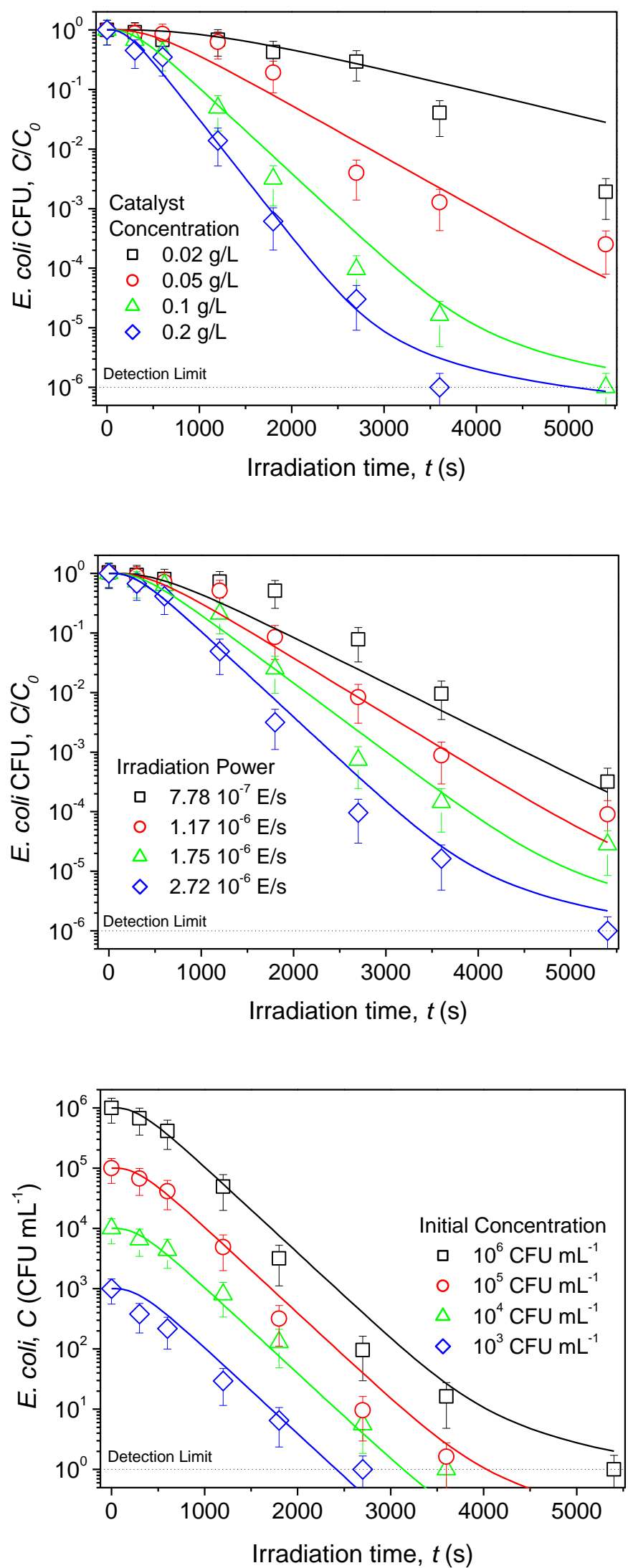

Figure 8. Experimental results (symbols) and simulation with the high irradiation flux 3parameter kinetic model represented by Eqs. (14) and (15) (lines). 

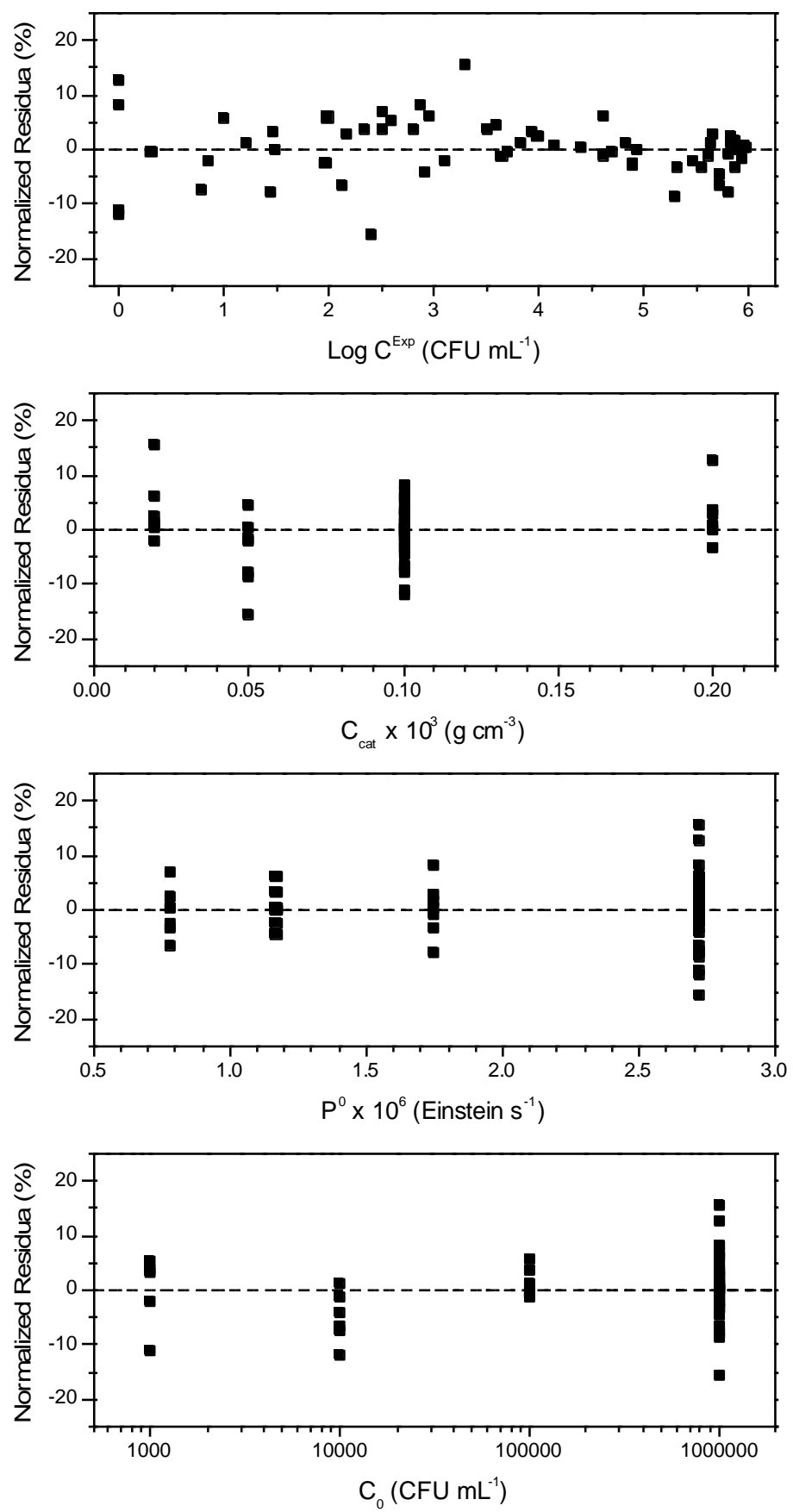

Figure B1. Distribution of the residua for the 4-parameter kinetic model represented by Eqs. (8) and (9). 

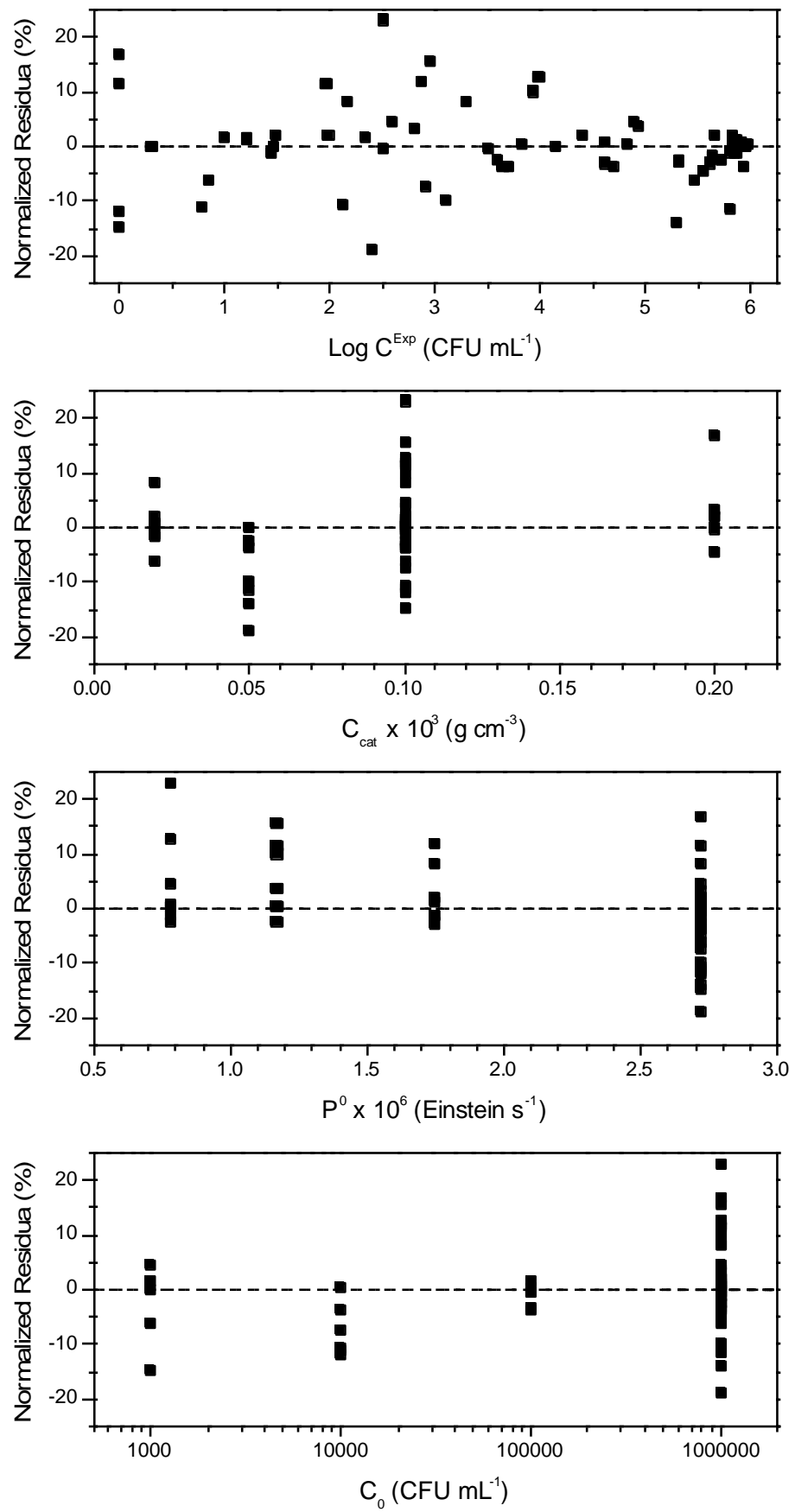

Figure B2. Distribution of the residua for the 3-parameter kinetic model represented by Eqs. (10) and (11). 

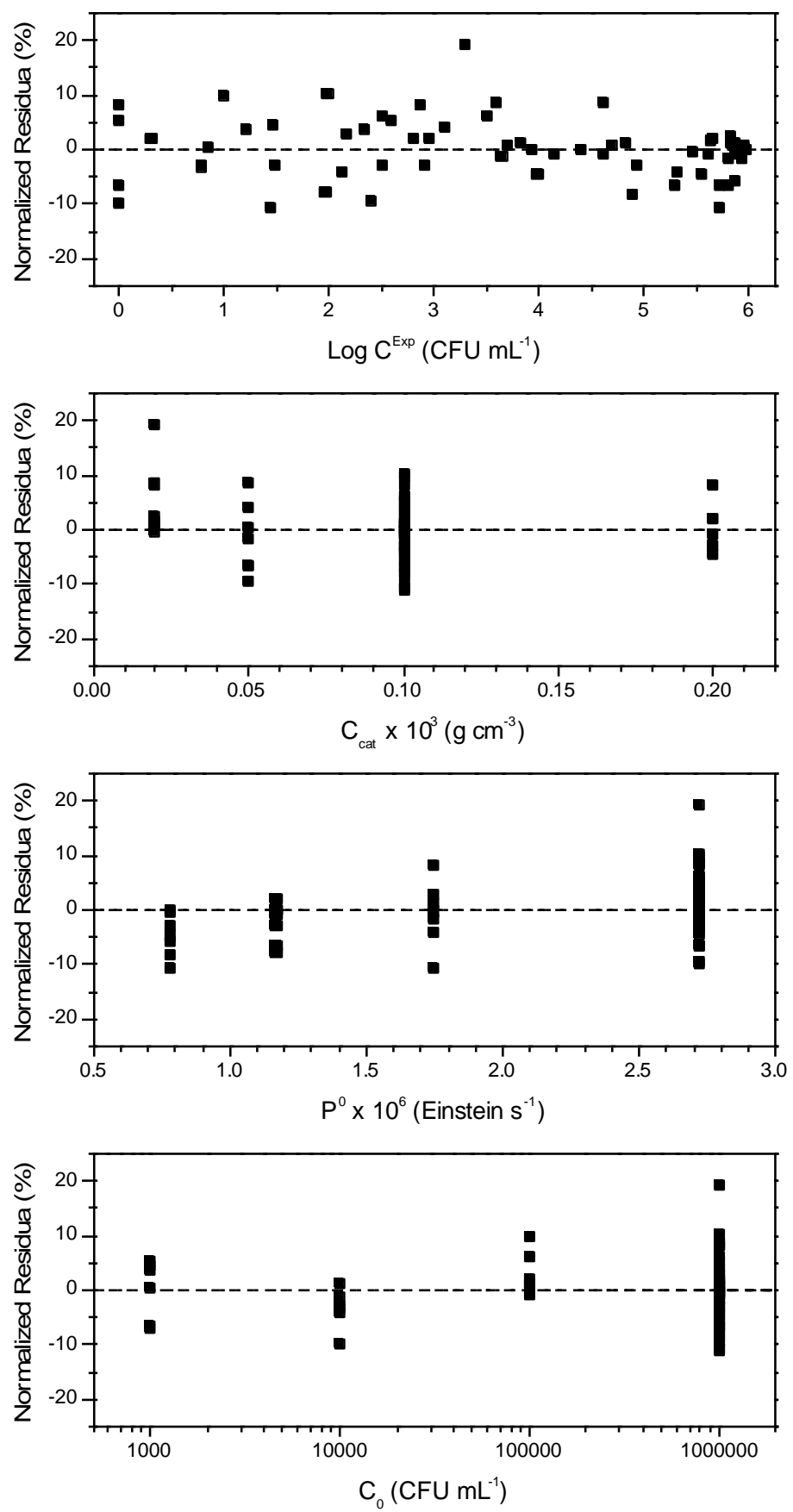

Figure B3. Distribution of the residua for the 3-parameter kinetic model represented by Eqs. (12) and (13). 